\title{
Macro-uncertainty and financial stress spillovers in the Eurozone
}

4th November 2019

\begin{abstract}
This paper studies macro-uncertainty and financial distress spillovers within the Eurozone. We propose a novel methodology to derive the indices of spillovers, by using a Global Vector autoregressive model fitted to data sampled at mixed-frequencies. We find that macrouncertainty and financial stress are relatively disconnected in the Eurozone. We also show that connectedness between core and periphery Eurozone countries is mainly occurring through financial stress and it decreases since the outbreak of the Eurozone sovereign debt crisis (with an increasing role played by peripheral countries). As a result, investors and policymakers should monitor separately macro-uncertainty and financial stress. Finally, we find that the mixed-frequency data should be taken into account in this context, otherwise, the spillovers are underestimated.
\end{abstract}

Keywords: Connectedness, Global VAR, Mixed Frequency Data, Financial Stress, Macro-uncertainty JEL Classification: C32, E44

\section{Acknowledgements}

We would like to thank the editor, S. Mallick, and two anonymous referees for the helpful comments, which have led to a significant improvement of the paper. 


\section{Introduction}

Uncertainty is a key driver of demand for funding firms investment plans and household consumption decisions, nonetheless, it also affects the supply of those funds provided through financial markets. While the former type of uncertainty is related to macroeconomic activity (e.g. GDP), the latter can be associated to financial stress. The recent empirical studies, for the US, find disconnect between macro and financial uncertainty. In particular, Jurado et al. (2015) find that the index of macroeconomic uncertainty they construct identifies far fewer episodes of turmoil than those captured by stock market volatility. Ludvigson et al. (2015) find that macro and financial uncertainty play different role in shaping real economic activity fluctuations.

In this paper, we seek to assess the degree of spillovers between macroeconomic uncertainty and financial stress across Eurozone countries. While a large number of studies analyse the role of uncertainty spillovers on the real economy (see Baker et al. (2016), Jurado et al. (2015)), we focus on spillovers of uncertainty. More specifically, we proxy macroeconomic uncertainty by a quarterly index of uncertainty about GDP growth (computed by Rossi and Sekhposyan (2017)) and financial stress is proxied by a monthly Country-Level Index of Financial Stress provided by the European Central Bank (see Duprey et al. (2017)). In order to rely on a relatively large sample of time series observations for each variable, we concentrate on the Eurozone countries for which data are available over an extended sample. The number of Eurozone countries is ten. Five of them are core Eurozone countries (Austria, Belgium, France, Germany, Netherlands) and the remaining ones are peripheral countries, PIIGS, (Portugal, Ireland, Italy, Greece and Spain). The analysis is carried out considering either a sub-sample period ending in 2009 (which includes, as a period of turmoil, only the Global Financial Crisis) or for the full sample period (1997-2015), which includes the Eurozone sovereign debt crisis as well. ${ }^{1}$

Financial stress spillovers have been investigated by Balakrishnan et al. (2011), Dovern and van Roye (2014), Apostolakis and Papadopoulos (2014, 2015), and Apostolakis (2016). Rossi and Sekhposyan (2017) explore the transmission of economic uncertainty shocks across countries. Our focus is on the analysis of spillovers (measured through forecast error variance decomposition analysis), within the Eurozone, from the core to the periphery, and vice versa. More specifically, the analysis of connectedness between core and periphery is disaggregated, first, by distinguishing between the macro-uncertainty and financial stress and then by investigating the role played by each specific country.

Second, our contribution is methodological. To our knowledge, we are first to derive indices of spillovers by fitting a Global Vector Autoregression (GVAR) to series sampled at mixed frequencies. The indices of connectedness are obtained by following the suggestions of Greenwood-Nimmo et al. (2015), who extend Diebold and Yilmaz (2012, 2014, henceforth DY) VAR-based analysis

\footnotetext{
${ }^{1}$ We also consider a sub-sample period ending in 2008:Q2 (which excludes the Global Financial Crisis). As the findings (available upon request) draw similar conclusions as for the 1997-2009 sub-sample, we do not report the results.
} 
of spillovers to a Global Vector Autoregressive model.

The empirical findings show that macro-uncertainty and financial stress blocks are disconnected, given that spillovers from each block account only for a quarter of the forecast error variance. Therefore, our findings suggest that investors and policymakers should separately monitor macro-uncertainty and financial stress when taking decisions. ${ }^{2}$ Moreover, we find evidence of a decrease in the degree of connectedness between the core and periphery block since the outbreak of the Eurozone sovereign debt crisis. In addition, we find evidence of a shift in directional connectedness, since core (peripheral) countries are the triggers of the connectedness between macro-uncertainty and financial stress before (after) the Eurozone sovereign debt crisis. We also show that connectedness between core and periphery occurs mainly through financial stress, although it decreases during the Eurozone sovereign debt market crisis, given a strong decline in the financial stress spillovers from the core to the periphery. Moreover, we find that the main contributors to the (decreased) connectedness after the Eurozone sovereign debt crisis are Greece, Ireland and Spain.

Finally, empirical findings show that the use of data aggregated at low frequency would underestimate the degree of connectedness (hence, the degree of systemic risk), given that the spillover indices obtained through the estimation of the mixed-frequency GVAR are larger than the corresponding ones obtained through the estimation of the common-frequency GVAR (which is the standard approach). ${ }^{3}$ As argued by Ghysels (2016), the inclusion of the financial data sampled at a high-frequency is relevant because it results in a more informative sample than the one used in a standard common-frequency $(\mathrm{CF})$ approach.

The structure of this paper is as follows: Section 2 reviews the related literature and specifies our contribution; Section 3 explains the methodology; Section 4 describes the data; our main results are presented in Section 5 and 6; the robustness of the results to the choice of weighting scheme is presented in Section 7. Section 8 concludes.

\section{Literature review}

Conditional volatility models have been used to study macroeconomic uncertainty. Fountas et al. (2006) use the multivariate GARCH model fitted to monthly US industrial production and inflation to capture macroeconomic uncertainty. Henzel and Rengel (2017) use an Exponentially Weighted Moving Average to model the volatility of two common latent variables (extracted through a dynamic factor model) underlying US macroeconomic uncertainty. The first factor

\footnotetext{
${ }^{2}$ The empirical finding of the disconnect between macroeconomic uncertainty (a key driver of firms investment plans) and financial uncertainty (underlying different source of financing investments) is in line with the studies of Jurado et al. (2015) and of Ludvigson et al. (2015).

${ }^{3}$ To our knowledge, the study of Cotter et al. (2017) is the only one using the DY approach relying on the estimation of a VAR fitted to mixed-frequency data to analyse spillovers between the real and financial sides of the US economy. The authors show that additional high-frequency information produces estimated spillovers that are typically higher than those from an analogous common-frequency approach.
} 
captures business cycle uncertainty, while the second factor represents oil and commodity price uncertainty. Recently, stochastic volatility has been used to model macroeconomic uncertainty. More specifically, Jurado et al. (2015) use stochastic volatility of a latent variable extracted from a dynamic factor model fitted to a large set of macro-time series in the US. Alessandri and Mumtaz (2019) use the stochastic volatility of structural innovations underlying a structural VAR. While the previous studies focus only on the US, another strand of the literature broadens the focus to several countries. Baker et al. (2016) derive, for major world economies, an index of economic policy uncertainty, EPU, computed by combining uncertainty-related keywords in news publications. More recently, Rossi and Sekhposyan (2017) rely on the quantile of the unconditional distribution of forecast errors to derive an index of uncertainty about real economic activity for a number of Eurozone countries. In addition, authors examine the spillovers across the macroeconomic uncertainty indices of 17 Eurozone countries using Diebold and Yilmaz (2012) methodology. The focus of Rossi and Sekhposyan (2017) is on macroeconomic uncertainty spillovers, while we also consider spillovers across financial stress indices of Eurozone countries.

The empirical literature on the financial stress indices, monitoring the evolution of distress affecting different sectors of financial markets (mainly stocks, bonds, banking and foreign exchange), is growing. Our study is closely related to the literature that aims to quantify the financial stress spillovers across European financial markets by using Diebold and Yilmaz (2012) approach. Cotter and Suurlaht (2019) analyse financial spillovers among the five largest European economies: France, Germany, Italy, Spain and the UK. They find that, among the five indicators of risk considered (credit risk, real estate market risk, interest rate risk, interbank liquidity risk and stock market risk), those related to stock and the real estate markets lead the shocks transmission. Magkonis and Tsopanakis (2019) use the Diebold and Yilmaz approach to examine financial stress interconnectedness among PIIGS countries and Germany for the period 2001-2013. The markets considered are those for banking, bond, money and equity and the authors' findings show that Italian and Spanish markets are the main source of stress transmission in all markets, especially in banking and equity markets. Contrary to common wisdom, Portugal, Ireland, and mainly Greece, do not seem to play an important role in amplifying stress levels. Our focus, instead, is on the analysis of spillovers between core and periphery Eurozone countries. Moreover, we disaggregate core-periphery spillover analysis by distinguishing between macro-uncertainty and financial stress spillovers, and then we investigate the role played by each specific country.

While there are several structural VAR studies exploring the linkages between financial stress and macroeconomic fundamentals for the Eurozone (see the analysis of the monetary-financial stability nexus by Granville and Mallick (2009) and by Mallick and Sousa (2013)), the literature on economic uncertainty-financial stress spillovers is scarce. The study of Candelon et al. (2018) assesses financial interconnectedness among 13 equity markets (including developed and emerging countries). The authors extend the measure of connectedness put forward by Diebold and Yilmaz by allowing for non-linear effects through the estimation of a nonlinear Threshold VAR model 
whose regimes depend on the level of various uncertainty measures (economic, political or macroeconomic uncertainty). The authors find that the global equity market is more interconnected during periods of high uncertainty than during the periods of low uncertainty.

We differ from the previous literature by focusing on uncertainty proxies, rather than real economic indicators. To the best of our knowledge, the paper by Liow et al. (2018) is the only study (based on a common frequency VAR) to derive the Diebold and Yilmaz indices of total and directional connectedness among economic policy uncertainty (measured by the EPU index) and financial stress arising not only in the stock market, but also in the real estate, bond and currency markets of seven major world economies. ${ }^{4}$ However, instead of relying on the economic policy uncertainty (EPU index), we use GDP growth uncertainty index.

\section{Empirical methodology}

We compute the macro-financial spillovers using the generalized connectedness measures (GCM) developed by Greenwood-Nimmo et al. (2015), who extend the Diebold and Yllmaz (2014) generalised forecast error variance decomposition analysis to a GVAR model. The GVAR model is based on 10 country-specific VARs, each including the same set of variables sampled at different frequencies: (i) quarterly real economy indicators (i.e. GDP growth uncertainty index by Rossi and Sekhposyan (2017)) and (ii) monthly financial indicators (i.e. country-specific indicators of financial stress, by Duprey et al. (2017)). More specifically, we extend the country-specific mixedfrequency VAR methodology put forward by Ghysels (2016) to a GVAR, and we also compare the empirical findings with the standard common-frequency GVAR model (based on aggregating the high-frequency series to a low-frequency one).

\subsection{Global VAR model using mixed-frequency data}

The GVAR model is constructed by combining 10 country-specific models (Austria, Belgium, France, Germany, Netherlands, Greece, Ireland, Italy, Portugal and Spain) indexed by $i=$ $1,2 \ldots N$. Country model $i$ includes the following variables sampled at different frequencies: a quarterly GDP growth uncertainty index $U G D P_{i}$ (i.e. a low-frequency variable) and a monthly indicator of financial stress $C L I F S_{i}$ (i.e. a high-frequency variable). A high-frequency series is observed $m=3$ times during a low-frequency period $t$. Let $C L I F S_{i}(t, 1)$ be the first highfrequency observation in low-frequency period $t$ (i.e. the first monthly observation of the quarter $t$ ), a $C L I F S_{i}(t, 2)$ - the second observation, and $C L I F S_{i}(t, 3)$ - the last one. In a mixedfrequency VAR, all observations of period $t$ are stacked into a column vector by treating the $m$ observations of the high-frequency series as if they were distinct endogenous variables.

\footnotetext{
${ }^{4}$ See also Sun et al. (2017) provide an analysis of short-run co-movement between the EPU index and financial stress, by using a multi-scale correlation framework.
} 
A mixed-frequency vector of endogenous variables for country $i$ is composed of $k_{i}=4$ variables and is given as:

$$
Z_{i, t}=\left[C \operatorname{LIF} S_{i}(t, 1), C L I F S_{i}(t, 2), C L I F S_{i}(t, 3), U G D P_{i}(t)\right]^{\prime}
$$

A corresponding standard common-frequency (CF) data vector for country $i$, which contains both the high-frequency and the low-frequency variables observed at the low frequency (i.e. quarter), has the following composition:

$$
Z_{i, t}^{L}=\left[C L I F S_{i}(t), U G D P_{i}(t)\right]^{\prime}
$$

where the monthly variable is aggregated to the quarterly frequency as: $\frac{1}{3} \sum_{j=1}^{3} C L I F S_{i}(t, j)$. Therefore, while the MF-VAR has four endogenous variables, the CF-VAR has only two endogenous variables.

Consider now each country $i$ represented by a mixed-frequency vector autoregressive model augmented by a set of foreign variables $Z_{i, t}^{*}$. Specifically, a MF-VARX $(1,1)$ model is set up for each country $i$ as:

$$
Z_{i, t}=c_{i}+\Gamma_{i} Z_{i, t-1}+\Lambda_{i 0} Z_{i, t}^{*}+\Lambda_{i 1} Z_{i, t-1}^{*}+u_{i, t}
$$

for $i=1, \ldots, N$ countries and $t=1, \ldots, T$ low-frequency time periods. ${ }^{5}$ Furthermore, $Z_{i, t-1}$ is a $k_{i} \times 1$ vector of lagged country-specific (domestic) variables (in eq. (1)), $Z_{i t}^{*}$ is a $k_{i} \times 1$ vector of country-specific foreign variables, $c_{i}$ is a constant and $u_{i, t}$ is a $k_{i} \times 1$ vector of serially uncorrelated innovations, with $\Sigma_{u_{i}}$ being a sample variance-covariance matrix of the reduced-form residuals; $\Gamma_{i}$ is a $k_{i} \times k_{i}$ coefficient matrix associated to lagged domestic variables, $\Lambda_{i 0}$ and $\Lambda_{i 1}$ are $k_{i} \times k_{i}$ coefficient matrices related to, respectively, contemporaneous and lagged foreign variables. ${ }^{6}$

The vector of foreign variables $Z_{i, t}^{*}$ in a country-specific MF-VARX is constructed as a weighted average of other countries' variables:

$$
Z_{i, t}^{*}=W_{i} Z_{t}
$$

where $Z_{t}=\left[Z_{1, t}^{\prime}, Z_{2, t}^{\prime}, \ldots, Z_{N, t}^{\prime}\right]^{\prime}$ is a $k \times 1$ vector including all endogenous variables of the system $\left(k=\sum_{i=1}^{N} k_{i}=40\right.$ in our study in a MF case) and $W_{i}$ is a $k_{i} \times k$ link matrix:

$$
W_{i}=\left(w_{i 1} I_{k_{i}}, \cdots, \quad w_{i i} I_{k_{i}}, \cdots, \quad w_{i N} I_{k_{i}}\right)
$$

where $w_{i i}=0$ is a $4 \times 4$ matrix and $w_{i g}$ is a $4 \times 4$ diagonal matrix with fixed trade weights on

\footnotetext{
${ }^{5}$ Due to the small number of quarterly observations i.e. the 72 available observations, we set lag orders to one. Then, we estimate a VARX $(1,1)$ model by using an OLS estimator for each country separately.

${ }^{6}$ Similarly, we can implement a corresponding standard VARX model by considering the low-frequency vector (2) in eq. (3) instead of mixed-frequency vector (1).
} 
the main diagonal. The trade weights are obtained from the BIS over the 2011-2013 period (see Table 1). ${ }^{7}$ For instance, the link matrix for Austria (AT) is as follows:

$$
W_{A T}=\left(\begin{array}{cccccccccc}
0 & 0 & 0 & 0 & w_{A T, B E} & 0 & 0 & 0 & \cdots & 0 \\
0 & 0 & 0 & 0 & 0 & w_{A T, B E} & 0 & 0 & \cdots & 0 \\
0 & 0 & 0 & 0 & 0 & 0 & w_{A T, B E} & 0 & \cdots & 0 \\
0 & 0 & 0 & 0 & 0 & 0 & 0 & w_{A T, B E} & \cdots & w_{A T, E S}
\end{array}\right)
$$

The weight $w_{A T, g}$ in (6) is obtained from Table 1 . Consequently, the foreign variables in $Z_{i, t}^{*}$ eq. (4) for Austria are given by:

$$
Z_{A T, t}^{*}=W_{A T} Z_{t}=\left(\begin{array}{c}
C L I F S_{A T}^{*}(t, 1) \\
C L I F S_{A T}^{*}(t, 2) \\
C L I F S_{A T}^{*}(t, 3) \\
U G D P_{A T}^{*}(t)
\end{array}\right)
$$

In the first stage of the analysis, each country-specific MF-VARX in (3) is estimated by using OLS like a standard country-specific CF-VARX. In the second stage, the $N=10$ models are combined in the form of a global model. Suppose $S_{i}$ is a $k_{i} \times k$ selection matrix that picks up country-specific variables from the global vector of mixed-frequency endogenous variables $\left(Z_{t}\right)$ such that:

$$
Z_{i, t}=S_{i} Z_{t}
$$

Then, by substituting (4) and (8) in (3), we rewrite a country-specific MF-VARX(1) in terms of $Z_{t}$ :

$$
\left(S_{i} Z_{t}\right)=c_{i}+\Gamma_{i}\left(S_{i} Z_{t-1}\right)+\Lambda_{i 0}\left(W_{i} Z_{t}\right)+\Lambda_{i 1}\left(W_{i} Z_{t-1}\right)+u_{i, t}
$$

Re-arrange:

$$
\left(S_{i}-\Lambda_{i 0} W_{i}\right) Z_{t}=c_{i}+\left(\Gamma_{i} S_{i}+\Lambda_{i 1} W_{i}\right) Z_{t-1}+u_{i, t}
$$

Re-name:

$$
G_{i} Z_{t}=c_{i}+H_{i} Z_{t-1}+u_{i, t}
$$

Finally, the GVAR model is built by simply stacking up all the $i=1,2, \ldots, N$ country-specific models in a global model:

\footnotetext{
${ }^{7}$ The use of trade weights is in line with the GVAR analysis of Cesa-Bianchi (2013) and Greenwood-Nimmo et al. (2015). We also show, in Section 7, that our results are robust to the choice of weighting scheme.
} 


$$
G Z_{t}=c+H Z_{t-1}+u_{t}
$$

where $G=\left(G_{1}^{\prime}, G_{2}^{\prime}, \ldots, G_{N}^{\prime}\right)^{\prime}, H=\left(H_{1}^{\prime}, H_{2}^{\prime}, \ldots, H_{N}^{\prime}\right)^{\prime}, c=\left(c_{1}^{\prime}, c_{2}^{\prime}, \ldots, c_{N}^{\prime}\right)^{\prime}$ and $u_{t}=\left(u_{1, t}^{\prime}, u_{2, t}^{\prime}, \ldots, u_{N, t}^{\prime}\right)^{\prime}$. If the $G$ matrix in (12) is non-singular, we can invert it and obtain a GVAR model in its reduced form:

$$
Z_{t}=\mu+F Z_{t-1}+\nu_{t}
$$

where $F=G^{-1} H, v_{t}=G^{-1} u_{t}$ and $\mu=G^{-1} c$.

\subsection{Generalized connectedness measures}

\subsubsection{Generalized forecast error variance decomposition (GFEVD)}

We use the connectedness measures proposed by Diebold and Yllmaz (2014)), based on the order-invariant generalised FEVD and extended to GVAR by Greenwood-Nimmo et al. (2015):

$$
G F E V D=\tilde{\theta}_{l \leftarrow j}(H)=\frac{\sigma_{u, j j}^{-1} \sum_{h=0}^{H-1}\left(e_{l}^{\prime} \Phi_{h} G^{-1} \Sigma_{u} e_{j}\right)^{2}}{\sum_{h=0}^{H-1} e_{l}^{\prime} \Phi_{h} \Sigma_{v} \Phi_{h}^{\prime} e_{l}}
$$

for $l, j=1, \ldots, k$, where $H=4,8$ forecast horizon, $\sigma_{u, j j}^{-1}$ are the standard deviations of the residual process of the $j$-th equation in the system (i.e. squared root of diagonal elements of $\Sigma_{u}$ matrix in (12)), $\Sigma_{v}=G^{-1} \Sigma_{u}\left(G^{-1}\right)^{\prime}, e_{l}\left(e_{j}\right)$ is a $k \times 1$ selection vector whose $l$-th $(j$-th) element is equal to unity and zeros elsewhere, the matrix $G$ is obtained from eq. (12). The $\Phi_{h}$ is a coefficient matrix from the infinite order moving average (MA) representation of the GVAR model in (13):

$$
Z_{t}=\sum_{h=0}^{\infty} \Phi_{h} \nu_{t-h}
$$

with $\Phi_{0}=I_{k}$ and $\Phi_{h}=F \Phi_{h-1}$ and the matrix $F$ is obtained from estimation of the reduced form model given in (13). The non-diagonality of $\Sigma_{v}$ implies that the sum of elements in each row of the variance decomposition does not need to sum to unity across $j$ (i.e. $\sum_{j=1}^{k} \theta_{l j}(H) \neq 1$ ). Therefore, in order to restore a variance shares interpretation to the GFEVD, we follow Diebold and Yilmaz (2012) to normalize each entry of the variance decomposition matrix by the row of sum as:

$$
\theta_{l \leftarrow j}(H)=\frac{\tilde{\theta}_{l \leftarrow j}(H)}{\sum_{j=1}^{k} \tilde{\theta}_{l \leftarrow j}(H)}
$$

such that $\sum_{j=1}^{k} \theta_{l j}(H)=1$ and $\sum_{l, j=1}^{k} \theta_{l j}(H)=k$. 


\subsubsection{The MF connectedness matrix}

The resulting connectedness matrix, for the MF-GVAR model with mixed-frequency data vector in (1), is given in a general form as:

$$
\mathbb{C}_{M F}^{(H)}(k \times k)=\left[\begin{array}{cccccc}
\theta_{1 \leftarrow 1}(H) & \theta_{1 \leftarrow 2}(H) & \theta_{1 \leftarrow m}(H) & \theta_{1 \leftarrow k_{1}}(H) & \cdots & \theta_{1 \leftarrow k}(H) \\
\theta_{2 \leftarrow 1}(H) & \theta_{2 \leftarrow 2}(H) & \theta_{2 \leftarrow m}(H) & \theta_{2 \leftarrow k_{1}}(H) & \ddots & \theta_{2 \leftarrow k}(H) \\
\theta_{m \leftarrow 1}(H) & \theta_{m \leftarrow 2}(H) & \theta_{m \leftarrow m}(H) & \theta_{m \leftarrow k_{1}}(H) & \cdots & \theta_{m \leftarrow k}(H) \\
\theta_{k_{1} \leftarrow 1}(H) & \theta_{k_{1} \leftarrow 2}(H) & \theta_{k_{1} \leftarrow m}(H) & \theta_{k_{1} \leftarrow k_{1}}(H) & \cdots & \theta_{k_{1} \leftarrow k}(H) \\
\vdots & \vdots & \vdots & \vdots & \ddots & \vdots \\
\theta_{k \leftarrow 1}(H) & \theta_{k \leftarrow 2}(H) & \theta_{k \leftarrow m}(H) & \theta_{k \leftarrow k_{1}}(H) & \cdots & \theta_{k \leftarrow k}(H)
\end{array}\right]
$$

for $H=4,8$, where $m=3, k_{1}=4, k=\sum_{i=1}^{N} k_{i}=40$ for $i=(1,2, \ldots, 10)$ countries. $^{8}$ For instance, the elements in the first row of the matrix (17) are the fraction of the $H$-step-ahead error variance in forecasting the financial distress in Austria in the first month of the quarter (variable 1 ) which is explained by a shock to: (i) itself (see the coefficient $\theta_{1 \leftarrow 1}(H)$ ); (ii) financial distress in Austria in the second month of the quarter (variable 2), measured by the coefficient $\theta_{1 \leftarrow 2}(H)$; (iii) financial distress in Austria in the last month of the quarter (variable 3), measured by the coefficient $\theta_{1 \leftarrow m}(H)$; (iv) quarterly GDP growth uncertainty in Austria (variable 4), measured by the coefficient $\theta_{1 \leftarrow k_{1}}(H)$. The last coefficient $\theta_{1 \leftarrow k}(H)$ in the first row of the matrix (17) measures the contribution of quarterly GDP growth uncertainty in Spain (which is the last of the 10 Eurozone countries considered, that is, variable 40), to explain the forecast error variance of the financial distress in Austria in the first month of the quarter.

The corresponding connectedness matrix for the CF-GVAR model, considering commonfrequency data vector (in eq. 2), has the form:

$$
\underset{(K \times K)}{\mathbb{C}_{C F}^{(H)}}=\left[\begin{array}{cccc}
\phi_{1 \leftarrow 1}(H) & \phi_{1 \leftarrow K_{1}}(H) & \cdots & \phi_{1 \leftarrow K}(H) \\
\phi_{K_{1} \leftarrow 1}(H) & \phi_{K_{1} \leftarrow K_{1}}(H) & \cdots & \phi_{K_{1} \leftarrow K}(H) \\
\vdots & \vdots & \ddots & \vdots \\
\phi_{K \leftarrow 1}(H) & \phi_{K \leftarrow K_{1}}(H) & \cdots & \phi_{K \leftarrow K}(H)
\end{array}\right]
$$

for $H=4,8$, where $K_{1}=2, K=\sum_{i=1}^{N} K_{i}=20$ for $i=(1,2, \ldots, 10)$ countries. For instance, the $\phi_{1 \leftarrow 1}(H)$ measures the fraction of the $H$-step-ahead error variance in forecasting the quarterly financial distress in Austria that is attributable to shocks in itself; the element $\phi_{1 \leftarrow K_{1}}(H)$ characterises the effects of the shocks to quarterly GDP growth uncertainty in Austria on the quarterly

\footnotetext{
${ }^{8}$ As in a common-frequency case, the generic element $\theta_{l \leftarrow j}(H)$ represents the proportion of the $H$-step-ahead FEVD of variable $l$ accounted by innovations in variable $j$. The contribution of the shock to the $l$-th variable itself is denoted by $\theta_{l \leftarrow l}(H)$, while the other elements of the $l$-th row, $l \neq j$, capture the spillovers from the other variables in the system to variable $l$.
} 
financial distress, and the element $\phi_{1 \leftarrow K}(H)$ denotes the contribution of the quarterly GDP growth uncertainty in Spain to the quarterly financial distress in Austria.

\section{First stage aggregation}

The MF connectedness matrix in (17) incorporates a large volume of information on the spillovers between the variables in the system, resulting in $40^{2}$ elements compared to $20^{2}$ elements in the CF connectedness matrix in (18). In the MF form, the dynamics between the GDP growth uncertainty and financial distress in each country $i$ is characterised not by a single element of the GFEVD, like in a CF case, but by multiple elements. For instance, the sub-array $\left[\theta_{1 \leftarrow k_{1}}(H), \theta_{2 \leftarrow k_{1}}(H), \theta_{m \leftarrow k_{1}}(H)\right]^{\prime}$ in the MF-GFEVD (17) corresponds to a single element $\phi_{1 \leftarrow 2}(H)$ in the common-frequency GFEVD in (18). In order to facilitate interpretation and comparability between MF and CF connectedness matrices, we can transform the $\mathbb{C}_{M F}^{(H)}$ by grouping the elements related with $m$ high-frequency observations in each country $i$ into sub-arrays (blocks).

The MF-GFEVD $\mathbb{C}_{M F}^{(H)}$ in (17) expressed in an aggregated form is given by: ${ }^{9}$

$$
\begin{gathered}
\mathbb{C}_{A G G(M F)}^{(H)}(K \times K) \\
(K \times
\end{gathered}=\left[\begin{array}{cccc}
\Theta_{H_{1} \leftarrow H_{1}}(H) & \Theta_{H_{1} \leftarrow L_{1}}(H) & \cdots & \Theta_{H_{1} \leftarrow L_{N}}(H) \\
\Theta_{L_{1} \leftarrow H_{1}} & \Theta_{L_{1} \leftarrow L_{1}} & \cdots & \Theta_{L_{1} \leftarrow L_{N}} \\
\vdots & \vdots & \ddots & \vdots \\
\Theta_{L_{N} \leftarrow H_{1}} & \Theta_{L_{N} \leftarrow L_{1}} & \cdots & \Theta_{L_{N} \leftarrow L_{N}}
\end{array}\right] \quad \text { for } H=4,8
$$

where $K=20$, the index $H_{i}$ represents a high-frequency variable, i.e. the financial stress index and $L_{i}$ denotes a low-frequency variable, i.e. GDP growth uncertainty, for country $i=\{1,2, \ldots, 10\} .{ }^{10}$ For instance, the $(2 \times 2)$ upper-left block in eq. (19) corresponds to a $(4 \times 4)$ upper-left block of MF-GFEVD matrix in eq. (17), as follows:

$$
\begin{aligned}
& \underset{H_{1} \leftarrow H_{1}}{(1 \times 1)} \equiv\left[\begin{array}{ccc}
\theta_{1 \leftarrow 1}(H) & \theta_{1 \leftarrow 2}(H) & \theta_{1 \leftarrow m}(H) \\
\theta_{2 \leftarrow 1}(H) & \theta_{2 \leftarrow 2}(H) & \theta_{2 \leftarrow m}(H) \\
\theta_{m \leftarrow 1}(H) & \theta_{m \leftarrow 2}(H) & \theta_{m \leftarrow m}(H)
\end{array}\right]_{(m \times m)} \\
& \underset{(1 \times 1)}{\Theta_{H_{1} \leftarrow L_{1}}(H)} \equiv\left[\begin{array}{c}
\theta_{1 \leftarrow k_{1}}(H) \\
\theta_{2 \leftarrow k_{1}}(H) \\
\theta_{m \leftarrow k_{1}}(H)
\end{array}\right]_{(m \times 1)} \\
& \underset{(1 \times 1)}{\Theta_{L_{1} \leftarrow H_{1}}(H)} \equiv\left[\begin{array}{lll}
\theta_{k_{1} \leftarrow 1}(H) & \theta_{k_{1} \leftarrow 2}(H) & \theta_{k_{1} \leftarrow m}(H)
\end{array}\right]_{(1 \times m)}
\end{aligned}
$$

\footnotetext{
${ }^{9}$ Also, the individual elements of the MF global connectedness matrix in (17) could be used directly to study the connectedness measures.

${ }^{10}$ Note that $(H)$ stands for a forecast horizon and $H_{i}$ for a high-frequency variable for country $i$.
} 


$$
\begin{gathered}
\Theta_{L_{1} \leftarrow L_{1}}(H) \\
(1 \times 1)
\end{gathered} \equiv \begin{gathered}
\theta_{k_{1} \leftarrow k_{1}}(H) \\
(1 \times 1)
\end{gathered}
$$

where for country $i=1$ the $\Theta_{H_{1} \leftarrow L_{1}}(H)\left(\Theta_{L_{1} \leftarrow H_{1}}(H)\right)$ gathers together the elements measuring the contribution of the low-(high-) frequency variable to the H-step-ahead FEVD of the high(low-) frequency variable. Similarly, the elements $\Theta_{H_{1} \leftarrow H_{1}}\left(\Theta_{L_{1} \leftarrow L_{1}}\right)$ represent the contribution of the high-(low-) frequency variable to itself.

The elements in $\mathbb{C}_{A G G(M F)}^{(H)}$ eq. (19) are computed by aggregating the corresponding elements in $\mathbb{C}_{M F}^{(H)}$ eq. (17), as follows. The contribution of the high-frequency variable $\left(H_{g}\right)$ to the lowfrequency variable $\left(L_{i}\right)$ for countries $i, g=(1,2, \ldots, 10)$ is given by:

$$
\Theta_{L_{i} \leftarrow H_{g}}(H)=\sum_{j=1}^{m} \theta_{l \leftarrow j}(H)
$$

where $l$ is a low-frequency variable related to country $i$ (i.e. $U G D P_{i}(t)$ ) and $j=1,2,3$ is a high-frequency variable related to country $g$ (i.e. $\left.C L I F S_{g}(t, j)\right) .{ }^{11}$ Similarly, the contribution from a low-frequency variable $\left(L_{i}\right)$ to a high-frequency variable $\left(H_{g}\right)$ is given by:

$$
\Theta_{H_{g} \leftarrow L_{i}}(H)=\frac{1}{m} \sum_{j=1}^{m} \theta_{j \leftarrow l}(H)
$$

Moreover, the contribution from high-frequency variable $H_{g}$ in country $g$ to a high-frequency variable $H_{i}$ in country $i$ is given by:

$$
\Theta_{H_{i} \leftarrow H_{g}}(H)=\frac{1}{m} \sum_{l, j=1}^{m} \theta_{l \leftarrow j}(H)
$$

Finally, the elements $\Theta_{L_{i} \leftarrow L_{g}}(H)$ simply corresponds to $\theta_{l \leftarrow j}(H)$.

After aggregation, the $\mathbb{C}_{A G G(M F)}^{(H)}$ in eq. (19) and $\mathbb{C}_{C F}^{(H)}$ in eq. (18) have the same dimension $(K \times K)$ and can be interpreted in the same way.

\section{Second stage aggregation}

We follow the block aggregation approach proposed by Greenwood-Nimmo et al. (2015) to estimate the indices of directional connectedness at a more aggregate level than Diebold and Yilmaz. Firstly, the connectedness matrix in (19) is re-normalized as:

$$
\mathbb{C}_{R-A G G(M F)}^{(H)}=K^{-1} \mathbb{C}_{A G G(M F)}^{(H)}
$$

Therefore, the sum of all elements in matrix $\mathbb{C}_{R-A G G(M F)}^{(H)}$ is equal to one. This modification ensures that we may achieve a clear percentage interpretation of any desired block aggregation

\footnotetext{
${ }^{11}$ Note that $i$ may be equal to $g$.
} 
scheme (Greenwood-Nimmo et al. (2015)).

Since the GFEVDs are invariant to the ordering of the variables in the system, we can reorder the variables in $Z_{t}$ into $b$ groups. Then, the $\mathbb{C}_{R-A G G(M F)}^{(H)}$ can be expressed in block form as follows:

$$
\begin{gathered}
\mathbb{C}_{R-A G G(M F)}^{(H)} \\
(K \times K)
\end{gathered}=\left[\begin{array}{cccc}
B_{1 \leftarrow 1}^{(H)} & B_{1 \leftarrow 2}^{(H)} & \cdots & B_{1 \leftarrow b}^{(H)} \\
B_{2 \leftarrow 1}^{(H)} & B_{2 \leftarrow 2}^{(H)} & \cdots & B_{2 \leftarrow b}^{(H)} \\
\vdots & \vdots & \ddots & \vdots \\
B_{b \leftarrow 1}^{(H)} & B_{b \leftarrow 2}^{(H)} & \cdots & B_{b \leftarrow b}^{(H)}
\end{array}\right]
$$

The blocks lying on the main diagonal of $\mathbb{C}_{R-A G G(M F)}^{(H)}$ (i.e. $\left.B_{\alpha \leftarrow \alpha}(H)\right)$ contain all the withingroup FEVD contributions. The total within-group FEVD contribution for the $\alpha$-th group is:

$$
\mathcal{W}_{\alpha \leftarrow \alpha}^{(H)}=e_{K_{\alpha}}^{\prime} B_{\alpha \leftarrow \alpha}^{(H)} e_{K_{\alpha}}
$$

where $e_{K_{\alpha}}$ is a $K_{\alpha} \times 1$ vector of ones. The cross-group transmission (directional spillover) is indicated by $B_{\alpha \leftarrow \beta}^{(H)}(H)$ for $\alpha \neq \beta$. In particular, the spillover from group $\beta$ to group $\alpha$ is estimated as:

$$
\mathcal{F}_{\alpha \leftarrow \beta}^{(H)}=e_{K_{\alpha}}^{\prime} B_{\alpha \leftarrow \beta}^{(H)} e_{K_{\beta}}
$$

and the spillover to group $\beta$ from group $\alpha$ as:

$$
\mathcal{T}_{\beta \leftarrow \alpha}^{(H)}=e_{K_{\beta}}^{\prime} B_{\beta \leftarrow \alpha}^{(H)} e_{K_{\alpha}}
$$

In other words, $\mathcal{W}_{\alpha \leftarrow \alpha}^{(H)}, \mathcal{F}_{\alpha \leftarrow \beta}^{(H)}$ and $\mathcal{T}_{\beta \leftarrow \alpha}^{(H)}$ are equal to the sum of the elements in the related block $B_{\alpha \leftarrow \beta}^{(H)}$. By following these definitions, it is straightforward to obtain the group connectedness matrix form:

$$
\mathbb{B}_{(b \times b)}^{(H)}=\left[\begin{array}{cccc}
\mathcal{W}_{1 \leftarrow 1}^{(H)} & \mathcal{F}_{1 \leftarrow 2}^{(H)} & \cdots & \mathcal{F}_{1 \leftarrow b}^{(H)} \\
\mathcal{F}_{2 \leftarrow 1}^{(H)} & \mathcal{W}_{2 \leftarrow 2}^{(H)} & \cdots & \mathcal{F}_{2 \leftarrow b}^{(H)} \\
\vdots & \vdots & \ddots & \vdots \\
\mathcal{F}_{b \leftarrow 1}^{(H)} & \mathcal{F}_{b \leftarrow 2}^{(H)} & \cdots & \mathcal{W}_{b \leftarrow b}^{(H)}
\end{array}\right] \equiv\left[\begin{array}{cccc}
\mathcal{W}_{1 \leftarrow 1}^{(H)} & \mathcal{T}_{1 \leftarrow 2}^{(H)} & \cdots & \mathcal{T}_{1 \leftarrow b}^{(H)} \\
\mathcal{T}_{2 \leftarrow 1}^{(H)} & \mathcal{W}_{2 \leftarrow 2}^{(H)} & \cdots & \mathcal{T}_{2 \leftarrow b}^{(H)} \\
\vdots & \vdots & \ddots & \vdots \\
\mathcal{T}_{b \leftarrow 1}^{(H)} & \mathcal{T}_{b \leftarrow 2}^{(H)} & \cdots & \mathcal{W}_{b \leftarrow b}^{(H)}
\end{array}\right]
$$

Note that the dimension of the group connectedness matrix is $b^{2}<K^{2}$. Then, using (29) we can define the total from, to and net connectedness of the $\alpha$-th group as follows:

$$
\mathcal{F}_{\alpha \leftarrow *}^{(H)}=\sum_{\beta=1, \beta \neq \alpha}^{b} \mathcal{F}_{\alpha \leftarrow \beta}^{(H)}, \quad \mathcal{T}_{* \leftarrow \alpha}^{(H)}=\sum_{\beta=1, \beta \neq \alpha}^{b} \mathcal{T}_{\beta \leftarrow \alpha}^{(H)} \text { and } \quad \mathcal{N}_{* \leftarrow \alpha}^{(H)}=\mathcal{T}_{* \leftarrow \alpha}^{(H)}-\mathcal{F}_{\alpha \leftarrow *}^{(H)}
$$


where $\mathcal{F}_{\alpha \leftarrow *}^{(H)}$ measures the total contribution from all other groups to group $\alpha, \mathcal{T}_{* \leftarrow \alpha}^{(H)}$ is the total contribution to all other groups from group $\alpha$, and $\mathcal{N}_{* \leftarrow \alpha}^{(H)}$ measures the net connectedness $s$ of group $\alpha$. Finally, the total connectedness (spillover) index, $\mathcal{S}^{(H)}$, and the total domestic connectedness (within-group) index, $\mathcal{D}^{(H)}$, in terms of the $b$ groups is defined as follows:

$$
\mathcal{S}^{(H)}=\sum_{\alpha=1}^{b} \mathcal{F}_{\alpha \leftarrow *}^{(H)} \equiv \sum_{\alpha=1}^{b} \mathcal{T}_{* \leftarrow \alpha}^{(H)} \text { and } \quad \mathcal{D}^{(H)}=\sum_{\alpha=1}^{b} \mathcal{W}_{\alpha \leftarrow \alpha}^{(H)}
$$

\section{Data}

The proxy of financial conditions in each Eurozone country is the monthly Country-Level Index of Financial Stress (CLIFS) provided by the European Central Bank (see Duprey et al. (2017)). ${ }^{12}$ The CLIFS is a composite index derived from data representing three financial market segments: the stock price index for the equity market, 10-year government yields for the bond market, and the real effective exchange rate for the foreign exchange market. More specifically, stress in each financial market segment is captured by two indices: realized volatility and maximum loss over a two-year period. These are then combined using a portfolio aggregation approach. The composite index captures financial stress, which is reflected by (i) the uncertainty in market prices, (ii) sharp corrections in market prices, and (iii) the degree of commonality across the three financial market segments.

Since we also focus on macro-uncertainty, we rely on a novel real economic activity uncertainty dataset computed of Rossi and Sekhposyan (2017). The authors provide quarterly series of uncertainty for GDP growth. ${ }^{13}$ The GDP growth uncertainty index by Rossi and Sekhposyan (2017) builds on the point forecasts from the Survey of Professional Forecasters administered by the European Central Bank. The index is based on a comparison of the realized forecast error and the unconditional distribution of forecast errors for that variable (proxied by the full sample of past forecast errors). If the realized forecast error is in the tail of the distribution, then the realization is very difficult to predict, thus, the macroeconomic environment is very uncertain. For each country, Rossi and Sekhposyan (2017) construct the overall as well as the positive (upside) and negative (downside) uncertainty indices. ${ }^{14}$

All the series are plotted in the Appendix. Figure 1 presents the monthly CLIFS for the period from April 1997 to March 2015. Panel (a) shows the CLIFS for the core Eurozone countries (Austria, Belgium, France, Germany and the Netherlands) and panel (b) the same for the PIIGS countries (Greece, Ireland, Italy, Portugal and Spain). By construction, the CLIFS values vary

\footnotetext{
${ }^{12}$ The data is available at Statistical Data Warehouse, ECB: https://sdw.ecb.europa.eu/.

${ }^{13}$ The data is available at: http://www.tateviksekhposyan.org/. The authors rely on the methodology developed by Rossi and Sekhposyan (2015). The Baker et al. (2016) index of economic policy uncertainty would be another suitable candidate for the analysis, but it is available only for few Eurozone countries: France, Germany, Italy, Spain and the Netherlands.

${ }^{14}$ Positive (negative) uncertainty indicates that realized output growth is higher (lower) than expected.
} 
between 0 and 1, with large values indicating the high level of stress associated with the Global Financial Crisis and the Eurozone debt crisis. Furthermore, Figure 2 presents country-specific quarterly GDP growth uncertainty series from 1997:Q2 to 2015:Q1. Panel (a) plots the series for core Eurozone countries and panel (b) the same for PIIGS countries. We focus on the overall index of output growth uncertainty, which, by construction, varies between 0.5 and 1 . While before 2007 the degree of co-movement among core countries is higher than among peripheral countries, it increases for both group of countries during the Global Financial Crisis and at the beginning of the Eurozone debt crisis (between 2007 and 2010).

\section{$5 \quad$ LR test of MF vs CF Global VAR}

We assess whether the aggregation of high-frequency information generates a loss of information through LR test statistics computed for each country-specific VARX model, that is, a VAR augmented by the current and lagged values of the exogenous variable (capturing the impact of the foreign variables). More specifically, we follow Bacchiocchi et al. (2018), and we compare the log-likelihood of the unrestricted model $\left(l^{u}\right.$, i.e. MF-VARX), with the one for the restricted model $\left(l^{r}\right.$, i.e. CF-VARX). Table 2 shows the LR test statistics. We can observe that the null of equivalence between the traditional CF-VARX and the MF-VARX is strongly rejected. The results suggest that each of the estimated MF-VARX models provides more accurate results than the traditional CF-VAR. Therefore, aggregating the mixed-frequency data to a low frequency generates a loss of information. However, for the purpose of comparison, in Section 6 we will provide the results both for the MF Global VAR and CF Global VAR.

\section{Spillover analysis}

Since we are interested in exploring whether there has been a change in macro-financial uncertainty spillovers since the Eurozone sovereign debt crisis period onwards, we focus on a subsample period spanning from 1997:Q2 to 2009:Q4 and also on the full sample period spanning from 1997:Q2 to 2015:Q1.

In the empirical analysis, we consider various block schemes. We start from the aggregate results across the ten countries and follow with the country-specific results. The results for different block schemes are shown in Tables $3-6$. The figures in Tables $3-6$ are percentages of the total system-wide FEVD, and they are presented for the full sample and a sub-sample. Moreover, we focus on two forecast horizons $H=4,8$ quarters. ${ }^{15}$ The mixed-frequency GVAR model results are presented in panels (A), and the corresponding results for a common-frequency GVAR model are given in panels (B) of Tables 3 - 6 .

\footnotetext{
${ }^{15}$ The results for other forecast horizons $H=1,2, \ldots, 12$ quarters are available upon request.
} 


\subsection{Macro-financial connectedness}

We aim, first, to investigate how close are macroeconomic uncertainty and financial stress in the Eurozone. For this purpose, we estimate the degree of connectedness between GDP growth uncertainty and financial distress considering two blocks: (i) the macro-uncertainty block, (ii) the financial stress block. The former is constructed by aggregating the 10 countries' FEVD of GDP growth uncertainty, and the latter is obtained by aggregating the 10 countries' FEVD of financial distress. The connectedness measures between the two blocks are presented in Table 3 . The results on the main diagonal show the within-group spillovers and the off-diagonal elements represent the cross-block (directional) spillovers (see eq. (29)).

Inspection of Table 3 panel (A) shows that, in line with the empirical findings of Jurado et al. (2015) and Ludvigson et al. (2015) for the US, Eurozone macro-uncertainty and financial stress (capturing uncertainty in financial markets) are relatively disconnected. More specifically, if we consider a forecast horizon equal to a year $(H=4)$, we find that the sum of cross-block variance shares (off-diagonal elements of Table 3, panel (A)) account only for a quarter of the system-wide FEVD. Moreover, total connectedness does not change when we shift the focus from sub-sample to full sample analysis, which includes the period of the Eurozone sovereign debt crisis. A similar pattern is observed if we consider a forecast horizon equal to two years $(H=8)$. More specifically, total connectedness between macro-uncertainty and financial stress accounts for $28 \%$ of the system's FEVD (in a sub-sample and full sample analysis).

As for the directional spillover results, if we consider a forecast horizon equal to a year $(H=4)$, then we observe that there is a decrease (from $15.99 \%$ to $10.74 \%$ ) in the spillovers from financial market stress to GDP uncertainty when we shift the focus from sub-sample to full sample analysis (which also includes the Eurozone sovereign debt crisis). Moreover, we observe an increase (from $9.97 \%$ to $14.52 \%$ ) in the spillover from GDP uncertainty to financial stress. A similar pattern is observed if we consider a forecast horizon equal to two years $(H=8)$, since there is a decrease (from $18.49 \%$ to $12.85 \%$ ) in the contribution from financial stress to GDP uncertainty and an increase (from $9.68 \%$ to $14.93 \%$ ) in the spillover from GDP uncertainty to financial stress when we shift the focus from sub-sample to full sample analysis.

We also compare the mixed-frequency results with the results obtained using a commonfrequency approach (see panel (B) of Table 3). Total connectedness (sum of the off-diagonal elements) between GDP growth uncertainty and financial stress obtained by the common-frequency approach is slightly lower than the connectedness index obtained by using the MF approach (i.e. $23 \%$ for the $\mathrm{CF}$ approach vs $25 \%$ for the MF approach, at $H=4$ ). Moreover, our findings are in line with those of Cotter et al. (2017). The authors, using a MF-VAR, analyse macro-financial spillovers in the US for the sample period running from 1975 to 2015 and find that the index of total connectedness for the CF and MF models is equal to $16.38 \%$ and $24.79 \%$, respectively. 


\subsection{Regional connectedness}

In the second step, we analyse the macro uncertainty and financial stress transmission between the periphery and core blocks of the Eurozone. The findings in Table 4 panel (A) suggest a decrease in cross-regional connectedness (given by a sum of off-diagonal elements) from $31.42 \%$ to $25.41 \%$ (at $H=4$ ) once we shift from the sub-sample period preceding the Eurozone sovereign debt crisis to the full sample. Similarly, if we consider a forecast horizon of two years $(H=8)$, we observe a decrease in cross-regional connectedness from $33.32 \%$ to $28.73 \%$. This finding is in line with the empirical studies of Cipollini et al. (2015), Ehrmann and Fratzscher (2017) and Caporin et al. (2018), who find evidence of segmentation among Eurozone sovereign bond markets during the Eurozone sovereign debt market crisis period.

Moreover, in line with the empirical findings of Antonakakis and Vergos (2013), FernándezRodríguez et al. (2016), and De Santis and Zimic (2018), we observe a shift in the origin of connectedness relationships since the beginning of the Eurozone sovereign debt crisis. ${ }^{16}$ In particular, while core countries are the triggers of the connectedness relationship in the sub-sample period, PIIGS are the countries driving connectedness in the full sample period. More specifically, if we consider a forecast horizon equal to a year $(H=4)$, and if we shift the focus from sub-sample to full sample analysis (which includes the Eurozone sovereign debt crisis), then we observe a decrease in the spillovers from core to periphery countries (from $19.92 \%$ to $11.35 \%$ ) and an increase in the spillovers from periphery to core countries (from $11.50 \%$ to $13.88 \%$ ). If the focus is on a horizon equal to two years $(H=8)$, then spillovers from the periphery to core countries tend to increase from $12.88 \%$ to $17.33 \%$ when we shift from sub-sample to full sample analysis.

Furthermore, in line with the empirical findings of Fernández-Rodríguez et al. (2016) and De Santis and Zimic (2018), we observe a decrease (from $38.5 \%$ to $36.12 \%$ ) in the degree of connectedness within core countries (the upper-left element) when we shift the focus from subsample to full sample analysis. However, in line with Antonakakis and Vergos (2013) and unlike Fernández-Rodríguez et al. (2016) and to De Santis and Zimic (2018), we find an increase (from $30 \%$ to $38.5 \%$ ) in the degree of connectedness within PIIGS countries.

The results obtained by a common-frequency approach (see panel (B) in Table 4) indicate that the spillovers within both country groups (diagonal elements) increase once we move to the period including the Eurozone sovereign debt crisis. Moreover, the CF model suggests smaller directional spillovers than those obtained from Global MF VAR.

\footnotetext{
${ }^{16}$ The Diebold and Yllmaz (2014) approach has been used by Antonakakis and Vergos (2013), FernándezRodríguez et al. (2016) and De Santis and Zimic (2018). While Antonakakis and Vergos (2013) and FernándezRodríguez et al. (2016) focus on the Eurozone sovereign bond yield spread and volatility, respectively, and they use the general impulse response approach, De Santis and Zimic (2018) use a structural VAR fitted to Eurozone sovereign bond yields identified through sign restrictions.
} 


\subsubsection{Core-periphery connectedness: the role of financial stress and macro-uncertainty}

Further, we examine whether the main drivers of connectedness between core and periphery are financial stress or macro-uncertainty and whether the role of these drivers has changed over the years. In particular, we concentrate on four blocks: (i) GDP growth uncertainty in core countries, (ii) GDP growth uncertainty in PIIGS countries, (iii) financial distress in core countries, and (iv) financial distress in PIIGS countries. The results for the full sample and sub-sample (i.e. before the Eurozone sovereign debt crisis) are presented in Table 5.

We find that core-periphery spillovers mainly occur through financial stress (see panel A). More specifically, if we focus on Panel A.1, then we can observe that, for a forecast horizon equal to one year, core-periphery spillovers occurring only through financial stress are equal to $16.1 \%$ over the period preceding the Eurozone debt crisis, and they decrease to $9.3 \%$ once we consider the full sample. ${ }^{17}$ The main trigger of the disconnect between core and periphery is the strong decline in the financial stress spillovers from core to periphery countries, from $11.5 \%$ to $4.0 \%$. This finding confirms the empirical findings of Cipollini et al. (2015), Ehrmann and Fratzscher (2017) and Caporin et al. (2018), who find evidence of segmentation (during the Eurozone sovereign debt market crisis period) by focusing only on Eurozone sovereign bond markets.

The core-periphery spillovers occurring only through macro-uncertainty (sum of the elements in row 3, column 1 and in row 1, column 3 of each $4 \times 4$ matrix in panel A.1) are equal to $4 \%$ and $4.6 \%$ in the sub-sample and full sample periods, respectively.

It is also important to note that Table 5 highlights the role played by the core countries in system-wide risk through financial stress before the Eurozone debt crisis, given that they are net donors of financial stress spillovers (see sub-sample results, panel A.2 and A.4). In particular, we observe a decrease (from $10.5 \%$ to $-5.1 \%$, at $H=4$ ) in the net spillovers from the core EZ financial stress when we shift the focus from sub-sample to full-sample analysis. The peripheral Eurozone countries are net donors, both in terms of financial stress and real output growth uncertainty, during the period which includes the Eurozone sovereign debt crisis (see panel A.2 and A.4). In particular, the net spillover from the periphery macro-uncertainty and financial stress group increases (respectively, from $-3.9 \%$ to $1 \%$, and from $-4.5 \%$ to $1.3 \%$, at $H=4$, see panel A.2) once we shift the focus from sub-sample to full sample analysis. These findings are in line with Fernández-Rodríguez et al. (2016) and De Santis and Zimic (2018), who find a decline (increase) in directional connectedness from core (peripheral) to peripheral (core) countries during the sovereign debt crisis.

The common-frequency model results in panel B of Table 5 suggest smaller directional spillovers than those obtained from mixed-frequency data model (see panel A). In particular, if we consider a full-sample analysis in panel B.1, we find that core-periphery connectedness occurring through

\footnotetext{
${ }^{17}$ The financial stress spillovers between core and periphery are the sum of two elements of each $4 \times 4$ matrix (see panel A.1): the first is in row 4, column 2 and the second one is in row 2, column 4 .
} 
financial stress is 5 percentage points lower than the connectedness index obtained by the MF approach, while the core-periphery connectedness occurring through macro-uncertainty is around 0.5 percentage points lower for a common-frequency model. Moreover, contrary to the MF results, the common-frequency model suggests that periphery countries are net donors in terms of financial distress before the Eurozone sovereign debt crisis and they become net recipients once we also consider the Eurozone sovereign debt crisis (see panel B.2 and B.4).

\subsubsection{Core-periphery connectedness: country-specific analysis}

We also examine the role played by each country in driving connectedness between the core and the periphery and investigate whether the role of these drivers is changing over time. Table 6 records the within, from others and to others connectedness among countries in the system for the full sample and sub-sample periods at forecast horizon $H=4,8$.

If we consider a forecast horizon of one year ( $H=4$ quarters), the total connectedness index decreases from $57.6 \%$ to $48.1 \%$ (see panel A.1) when we shift the focus from sub-sample to full sample analysis. If the focus is on a forecast horizon equal to two years ( $\mathrm{H}=8$ quarters), we observe a decrease in total connectedness from $62.33 \%$ to $52.86 \%$ (see panel A.2). This finding holds for the common-frequency approach (see panel B.1 and B.2), although the total from/to spillovers are smaller than those obtained through the mixed-frequency approach. In particular, the CF results in panel B.1 show the decrease in the total connectedness index from $43.71 \%$ to $36.52 \%$ (for $H=4$ ) when we shift the focus from sub-sample to full sample analysis.

Our MF results are in line with other empirical studies performing Diebold and Yilmaz (2012, 2014) forecast error variance decomposition analyses focusing only on sovereign debt markets. Evidence of bond market fragmentation due to the Eurozone sovereign debt crisis is given by Fernández-Rodríguez et al. (2016) and by De Santis and Zimic (2018), who find evidence of a decrease in connectedness among Eurozone sovereign yields.

The total net spillovers across five core and the five peripheral countries confirm the findings in Table 4 (see panels A.1-A.2), that is, before the Eurozone sovereign debt crisis, the main contributors to connectedness are core countries. More specifically, while Belgium, the Netherlands and Germany all show positive net indices (pointing at their roles as net donors), the net spillover indices for the five peripheral countries are all negative. Moreover, the total net spillovers across the five core and the five peripheral countries confirms that after the Eurozone sovereign debt crisis, the main contributors to connectedness are peripheral countries. More specifically, while Greece, Ireland and Spain all show positive net indices (pointing at their roles as net donors), the

only core country with a positive net spillover index is Germany. These results differ, to some extent, from those obtained by De Santis and Zimic (2018), who find evidence of sovereign bond yield spillovers only from Greece and Italy during the turmoil related to the Eurozone sovereign debt market crisis. 


\section{Robustness of MF-GVAR results}

In this section, we check for the robustness of our results to the choice of fixed trade weights. For this purpose, we re-estimated the mixed-frequency GVAR model using time-varying trade weights and financial weights (i.e we re-estimate the foreign variables in eq. (4)).

Time-varying trade weights, from the Bank for International Settlements (BIS) database, are available on a three-year average trade basis. We follow Eickmeier and $\mathrm{Ng}$ (2015) for computing financial weights. In particular, we use the BIS consolidated banking statistics to derive the share of borrowing of each country from the remaining ones. We use an average of quarterly banking claims over the 2005:Q1 - 2015:Q1 period for full sample analysis, and 2005:Q1 - 2009:Q4 for a sub-sample analysis (the period is limited due to data availability).

The robustness results are available in the online appendix. Since we observe (in line Dees et al. (2007)) that gradual and small changes in trade weights occur over the sample period, the indices of connectedness computed using fixed and time-varying trade weights are broadly identical. Moreover, the empirical findings are also robust to the use of financial weights. The only difference from previous findings is related to the role played by Ireland as the trigger of spillovers in the sub-sample period (for a forecast horizon equal to one year).

\section{Conclusions}

In this paper, we estimate the degree of connectedness between macro-uncertainty and financial distress within the Eurozone from 1997 to 2015. To our knowledge, this is the first study to use a GVAR model fitted to data sampled at different frequencies: a monthly Country-Level Index of Financial Stress and a quarterly index of uncertainty about GDP growth. Total and directional connectedness are computed by using the methodology developed by Greenwood-Nimmo et al. (2015), who extend the Diebold and Yilmaz (2012, 2014) VAR-based analysis of spillovers to a GVAR model.

The empirical findings suggest that macro-uncertainty and financial stress are relatively disconnected in the Eurozone, since the spillovers across the two blocks account only for $25 \%$ of the total Eurozone system-wide FEVD at a one-year forecast horizon. Therefore, our findings suggest that investors and policymakers should separately monitor macro-uncertainty and financial stress. We also find evidence of a disconnect between core and periphery countries since the outbreak of the Eurozone sovereign debt crisis. In particular, connectedness between core and periphery mostly occurs through financial stress and it decreases during the Eurozone sovereign debt crisis, given a strong decline in the financial stress spillovers from core to periphery. Moreover, we show that while core countries (in particular Germany, the Netherlands and Belgium) are the triggers of connectedness between macro-uncertainty and financial stress before the Eurozone sovereign debt crisis, periphery countries (in particular, Greece, Ireland and Spain) play an important role in 
driving connectedness once we consider the full sample period (including the Eurozone sovereign debt crisis). Finally, by comparing the results obtained through mixed-frequency and commonfrequency GVAR we find that the use of data aggregated at low frequency would underestimate the degree of connectedness (hence, the degree of systemic risk). These findings regarding interconnections between macro-uncertainty and financial stress should be taken into account by policy makers when implementing policies aiming at financial stability. 


\section{References}

Alessandri, P. and H. Mumtaz (2019). Financial regimes and uncertainty shocks. Journal of Monetary Economics 101, 31-46.

Antonakakis, N. and K. Vergos (2013). Sovereign bond yield spillovers in the euro zone during the financial and debt crisis. Journal of International Financial Markets, Institutions and Money 26, 258-272.

Apostolakis, G. (2016). Spreading crisis: Evidence of financial stress spillovers in the asian financial markets. International Review of Economics 83 Finance 43, 542-551.

Apostolakis, G. and A. P. Papadopoulos (2014). Financial stress spillovers in advanced economies. Journal of International Financial Markets, Institutions and Money 32, 128-149.

Apostolakis, G. and A. P. Papadopoulos (2015). Financial stress spillovers across the banking, securities and foreign exchange markets. Journal of Financial Stability 19, 1-21.

Bacchiocchi, E., A. Bastianin, A. Missale, and E. Rossi (2018). Structural analysis with mixedfrequency data: A midas-svar model of us capital flows. arXiv preprint arXiv:1802.00793.

Baker, S. R., N. Bloom, and S. J. Davis (2016). Measuring economic policy uncertainty. The Quarterly Journal of Economics 131(4), 1593-1636.

Balakrishnan, R., S. Danninger, S. Elekdag, and I. Tytell (2011). The transmission of financial stress from advanced to emerging economies. Emerging Markets Finance and Trade $47(\sup 2)$, $40-68$.

Candelon, B., L. Ferrara, and M. Joëts (2018). Global financial interconnectedness: A non-linear assessment of the uncertainty channel. Working Papers 661, Banque de France.

Caporin, M., L. Pelizzon, F. Ravazzolo, and R. Rigobon (2018). Measuring sovereign contagion in europe. Journal of Financial Stability 34, 150-181.

Cesa-Bianchi, A. (2013). Housing cycles and macroeconomic fluctuations: A global perspective. Journal of International Money and Finance 37, 215-238.

Cipollini, A., J. Coakley, and H. Lee (2015). The european sovereign debt market: from integration to segmentation. The European Journal of Finance 21 (2), 111-128.

Cotter, J., M. Hallam, and K. Yilmaz (2017). Mixed-frequency macro-financial spillovers. Koç University-TUSIAD Economic Research Forum Working Papers No. 1704.

Cotter, J. and A. Suurlaht (2019). Spillovers in risk of financial institutions. The European Journal of Finance, 1-28. 
De Santis, R. A. and S. Zimic (2018). Spillovers among sovereign debt markets: Identification through absolute magnitude restrictions. Journal of Applied Econometrics 33(5), 727-747.

Dees, S., F. d. Mauro, M. H. Pesaran, and L. V. Smith (2007). Exploring the international linkages of the euro area: a global var analysis. Journal of applied econometrics 22 (1), 1-38.

Diebold, F. X. and K. Yilmaz (2012). Better to give than to receive: Predictive directional measurement of volatility spillovers. International Journal of Forecasting 28(1), 57-66.

Diebold, F. X. and K. Yllmaz (2014). On the network topology of variance decompositions: Measuring the connectedness of financial firms. Journal of Econometrics 182(1), 119-134.

Dovern, J. and B. van Roye (2014). International transmission and business-cycle effects of financial stress. Journal of Financial Stability 13, 1-17.

Duprey, T., B. Klaus, and T. Peltonen (2017). Dating systemic financial stress episodes in the eu countries. Journal of Financial Stability 32, 30-56.

Ehrmann, M. and M. Fratzscher (2017). Euro area government bonds-fragmentation and contagion during the sovereign debt crisis. Journal of International Money and Finance 70, 26-44.

Eickmeier, S. and T. Ng (2015). How do us credit supply shocks propagate internationally? a gvar approach. European Economic Review 74, 128-145.

Fernández-Rodríguez, F., M. Gómez-Puig, and S. Sosvilla-Rivero (2016). Using connectedness analysis to assess financial stress transmission in emu sovereign bond market volatility. Journal of International Financial Markets, Institutions and Money 43, 126-145.

Fountas, S., M. Karanasos, and J. Kim (2006). Inflation uncertainty, output growth uncertainty and macroeconomic performance. Oxford Bulletin of Economics and Statistics 68(3), 319-343.

Ghysels, E. (2016). Macroeconomics and the reality of mixed frequency data. Journal of Econometrics 193(2), 294-314.

Granville, B. and S. Mallick (2009). Monetary and financial stability in the euro area: Procyclicality versus trade-off. Journal of International Financial Markets, Institutions and Money 19(4), 662-674.

Greenwood-Nimmo, M., V. H. Nguyen, and Y. Shin (2015). Measuring the connectedness of the global economy. Melbourne Institute Working Paper Series, No. wp2015n0\%..

Henzel, S. R. and M. Rengel (2017). Dimensions of macroeconomic uncertainty: A common factor analysis. Economic Inquiry 55(2), 843-877. 
Jurado, K., S. C. Ludvigson, and S. Ng (2015). Measuring uncertainty. American Economic Review 105(3), 1177-1216.

Liow, K. H., W.-C. Liao, and Y. Huang (2018). Dynamics of international spillovers and interaction: Evidence from financial market stress and economic policy uncertainty. Economic Modelling 68, 96-116.

Ludvigson, S. C., S. Ma, and S. Ng (2015). Uncertainty and business cycles: exogenous impulse or endogenous response? NBER Working Paper No. w21803..

Magkonis, G. and A. Tsopanakis (2019). The financial connectedness between eurozone core and periphery: A disaggregated view. Macroeconomic Dynamics, 1-26.

Mallick, S. K. and R. M. Sousa (2013). The real effects of financial stress in the eurozone. International Review of Financial Analysis 30,1-17.

Rossi, B. and T. Sekhposyan (2015). Macroeconomic uncertainty indices based on nowcast and forecast error distributions. American Economic Review 105(5), 650-55.

Rossi, B. and T. Sekhposyan (2017). Macroeconomic uncertainty indices for the euro area and its individual member countries. Empirical Economics 53(1), 41-62.

Sun, X., X. Yao, and J. Wang (2017). Dynamic interaction between economic policy uncertainty and financial stress: A multi-scale correlation framework. Finance Research Letters 21, 214221. 


\section{A Figures}

Figure 1: Country-Specific Indicators of Financial Stress (CLIFS)

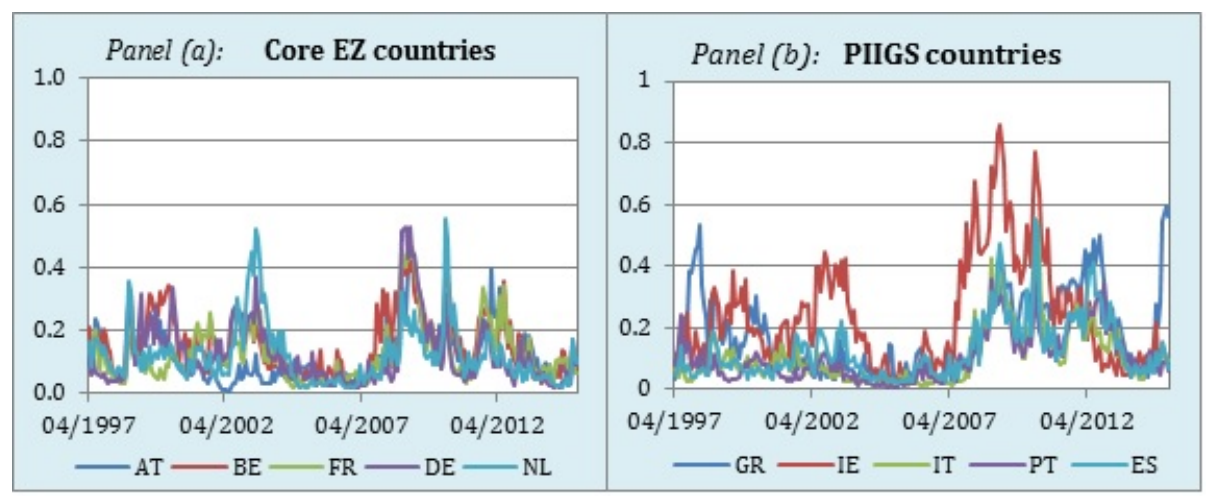

Figure 2: Country-Specific Output Growth Uncertainty Indices
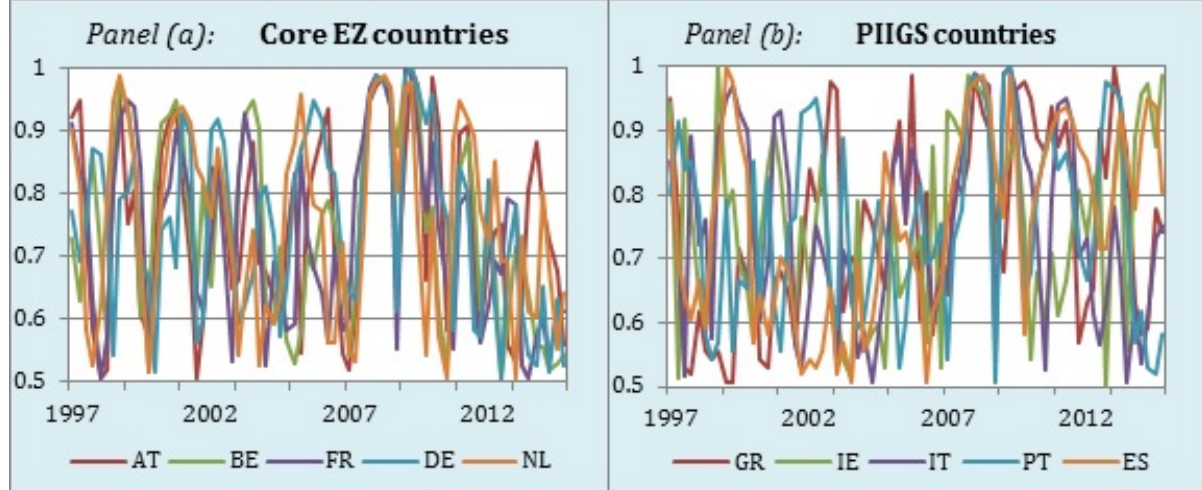

Notes: Horizontal axes show the forecast origin dates. 


\section{B Tables}

Table 1: Trade weights

\begin{tabular}{c|cccccccccc}
\hline$w_{i g}$ & AT & BE & FR & DE & NL & GR & IE & IT & PT & ES \\
\hline AT & 0 & 0.054 & 0.091 & 0.6 & 0.068 & 0.004 & 0.009 & 0.125 & 0.008 & 0.04 \\
BE & 0.025 & 0 & 0.212 & 0.342 & 0.182 & 0.005 & 0.066 & 0.102 & 0.011 & 0.056 \\
FR & 0.031 & 0.135 & 0 & 0.398 & 0.096 & 0.005 & 0.019 & 0.166 & 0.022 & 0.13 \\
DE & 0.119 & 0.138 & 0.249 & 0 & 0.169 & 0.008 & 0.021 & 0.181 & 0.021 & 0.094 \\
NL & 0.03 & 0.175 & 0.149 & 0.436 & 0 & 0.006 & 0.021 & 0.105 & 0.014 & 0.061 \\
GR & 0.032 & 0.086 & 0.122 & 0.306 & 0.099 & 0 & 0.018 & 0.242 & 0.01 & 0.085 \\
IE & 0.032 & 0.131 & 0.167 & 0.342 & 0.135 & 0.006 & 0 & 0.102 & 0.013 & 0.072 \\
IT & 0.051 & 0.099 & 0.209 & 0.385 & 0.104 & 0.014 & 0.018 & 0 & 0.016 & 0.104 \\
PT & 0.017 & 0.054 & 0.142 & 0.239 & 0.069 & 0.004 & 0.012 & 0.105 & 0 & 0.358 \\
ES & 0.025 & 0.073 & 0.246 & 0.305 & 0.084 & 0.007 & 0.019 & 0.156 & 0.085 & 0 \\
\hline
\end{tabular}

Table 2: LR test statistics for testing MF-VARX vs CF-VARX

\begin{tabular}{ccc}
\hline Country & Sub-sample (1997:Q2-2009:Q4) & Full sample (1997:Q2-2015:Q1) \\
\hline Austria & 463.56 & 592.89 \\
Belgium & 429.62 & 575.87 \\
France & 482.74 & 624.66 \\
Germany & 414.91 & 590.64 \\
Netherlands & 465.9 & 622.12 \\
Greece & 407.19 & 529.8 \\
Ireland & 362.81 & 499.31 \\
Italy & 520.31 & 693.7 \\
Portugal & 512.22 & 651.22 \\
Spain & 516.74 & 675.92 \\
\hline
\end{tabular}

Notes: The figures are the Likelihood Ratio, LR, statistics for testing the null of equivalence of MF-VARX with the traditional CF-VARX for each country $i=(\mathrm{AT}, \mathrm{BE}, \mathrm{FR}, \mathrm{DE}, \mathrm{NL}, \mathrm{GR}$,IE,IT,PT,ES), as suggested by Bacchiocchi et al. (2018). Rejection of the null hypothesis implies that aggregating the mixed-frequency series as in traditional CF-VARX generates a loss of information. The LR statistics are computed by comparing the log-likelihood of the unrestricted model, i.e. MF-VARX $\left(l^{u}\right)$, with the one associated with the restricted model, i.e. CF-VARX $\left(l^{r}\right)$. The test statistics $L R=-2\left(l^{r}-l^{u}\right)$ are asymptotically distributed as a $\chi 2$, with the degrees of freedom given by the number of restrictions on the coefficients of the MF-VARX model specified in eq. (3). More specifically, there are 38 restrictions: twelve are imposed on $\Gamma_{i}$, twelve on $\Lambda_{i 0}$, twelve on $\Lambda_{i}$ and two on $c_{i}$. We report the LR test statistics in the table and $p$-values (available upon request) are close to zero, suggesting a strong rejection of the null hypothesis. 
Table 3: Spillovers between financial stress and GDP growth uncertainty

\begin{tabular}{|c|c|c|c|c|c|c|c|c|}
\hline \multicolumn{9}{|c|}{ Panel A: Mixed Frequency Approach } \\
\hline \multicolumn{2}{|c|}{ Forecast horizon: } & \multicolumn{3}{|c|}{$\mathrm{H}=4$} & \multicolumn{4}{|c|}{$\mathrm{H}=8$} \\
\hline & \multicolumn{2}{|c|}{ Sub-sample } & \multicolumn{2}{|c|}{ Full sample } & \multicolumn{2}{|c|}{ Sub-sample } & \multicolumn{2}{|c|}{ Full sample } \\
\hline & \multicolumn{2}{|c|}{ 1997:Q2-2009:Q4 } & \multicolumn{2}{|c|}{ 1997:Q2-2015:Q1 } & \multicolumn{2}{|c|}{ 1997:Q2-2009:Q4 } & \multicolumn{2}{|c|}{ 1997:Q2-2015:Q1 } \\
\hline & UGDP & FS & UGDP & FS & UGDP & FS & UGDP & FS \\
\hline UGDP & 34.01 & 15.99 & 39.26 & 10.74 & 31.51 & 18.49 & 37.15 & 12.85 \\
\hline FS & 9.97 & 40.03 & 14.52 & 35.48 & 9.68 & 40.32 & 14.93 & 35.07 \\
\hline
\end{tabular}

Panel B: Common-Frequency Approach

\begin{tabular}{|c|c|c|c|c|c|c|c|c|}
\hline \multicolumn{3}{|c|}{ Forecast horizon: } & \multicolumn{4}{|l|}{$\mathrm{H}=4$} & \multicolumn{2}{|c|}{$\mathrm{H}=8$} \\
\hline & \multirow{2}{*}{\multicolumn{2}{|c|}{$\begin{array}{c}\text { Sub-sample } \\
\text { 1997:Q2-2009:Q4 }\end{array}$}} & \multirow{2}{*}{\multicolumn{2}{|c|}{$\begin{array}{c}\text { Full sample } \\
\text { 1997:Q2-2015:Q1 }\end{array}$}} & \multirow{2}{*}{\multicolumn{2}{|c|}{$\begin{array}{c}\text { Sub-sample } \\
\text { 1997:Q2-2009:Q4 }\end{array}$}} & \multirow{2}{*}{\multicolumn{2}{|c|}{$\begin{array}{c}\text { Full sample } \\
\text { 1997:Q2-2015:Q }\end{array}$}} \\
\hline & & & & & & & & \\
\hline & UGDP & $\mathrm{FS}$ & UGDP & FS & UGDP & FS & UGDP & FS \\
\hline UGDP & 31.46 & 18.54 & 47.38 & 2.62 & 30.63 & 19.37 & 46.84 & 3.16 \\
\hline $\mathrm{FS}$ & 4.39 & 45.61 & 20.48 & 29.52 & 5.65 & 44.35 & 23.22 & 26.78 \\
\hline
\end{tabular}

Notes: The source of spillover is a column, the row is a recipient. Within-group connectedness indices are on the main diagonal, and the off-diagonal elements show the to/from contributions. The total spillover index is estimated by summing the off-diagonal elements of the $(2 \times 2)$ matrix. 
Table 4: Regional Spillovers

\begin{tabular}{|c|c|c|c|c|c|c|c|c|}
\hline \multicolumn{9}{|c|}{ Panel A: Mixed Frequency Approach } \\
\hline \multicolumn{2}{|c|}{ Forecast horizon: } & \multicolumn{3}{|c|}{$\mathrm{H}=4$} & \multicolumn{4}{|c|}{$\mathrm{H}=8$} \\
\hline & \multirow{2}{*}{\multicolumn{2}{|c|}{$\begin{array}{c}\text { Sub-sample } \\
\text { 1997:Q2-2009:Q4 }\end{array}$}} & \multirow{2}{*}{\multicolumn{2}{|c|}{$\begin{array}{c}\text { Full sample } \\
\text { 1997:Q2-2015:Q1 }\end{array}$}} & \multirow{2}{*}{\multicolumn{2}{|c|}{$\begin{array}{c}\text { Sub-sample } \\
\text { 1997:Q2-2009:Q4 }\end{array}$}} & \multirow{2}{*}{\multicolumn{2}{|c|}{$\begin{array}{c}\text { Full sample } \\
\text { 1997:Q2-2015:Q1 }\end{array}$}} \\
\hline & & & & & & & & \\
\hline & Core & Periphery & Core & Periphery & Core & Periphery & Core & Periphery \\
\hline Core & 38.5 & 11.5 & 36.12 & 13.88 & 37.12 & 12.88 & 32.67 & 17.33 \\
\hline Periphery & 19.92 & 30.08 & 11.53 & 38.47 & 20.44 & 29.56 & 11.4 & 38.6 \\
\hline
\end{tabular}

Panel B: Common-Frequency Approach

\begin{tabular}{|c|c|c|c|c|c|c|c|c|}
\hline \multicolumn{3}{|c|}{ Forecast horizon: } & \multicolumn{4}{|l|}{$\mathrm{H}=4$} & \multicolumn{2}{|c|}{$\mathrm{H}=8$} \\
\hline & \multirow{2}{*}{\multicolumn{2}{|c|}{$\begin{array}{c}\text { Sub-sample } \\
\text { 1997:Q2-2009:Q4 }\end{array}$}} & \multirow{2}{*}{\multicolumn{2}{|c|}{$\begin{array}{c}\text { Full sample } \\
\text { 1997:Q2-2015:Q1 }\end{array}$}} & \multirow{2}{*}{\multicolumn{2}{|c|}{$\begin{array}{c}\text { Sub-sample } \\
\text { 1997:Q2-2009:Q4 }\end{array}$}} & \multirow{2}{*}{\multicolumn{2}{|c|}{$\begin{array}{c}\text { Full sample } \\
\text { 1997:Q2-2015:Q1 }\end{array}$}} \\
\hline & & & & & & & & \\
\hline & Core & Periphery & Core & Periphery & Core & Periphery & Core & Periphery \\
\hline Core & 39.4 & 10.6 & 40.97 & 9.03 & 37.61 & 12.39 & 38.09 & 11.91 \\
\hline Periphery & 12.97 & 37.03 & 9.54 & 40.46 & 14.02 & 35.98 & 9.46 & 40.54 \\
\hline
\end{tabular}

Notes: The source of spillover is a column, the row is a recipient. Within-group connectedness indices are on the main diagonal, and the off-diagonal elements show the to/from contributions. The total spillover index is estimated by summing the off-diagonal elements of $(2 \times 2)$ matrix. 
Table 5: Regional spillovers between financial stress and macro-uncertainty

Panel A: Mixed Frequency Approach

\begin{tabular}{|c|c|c|c|c|c|c|c|c|}
\hline \multirow[t]{3}{*}{$\mathrm{H}=\mathbf{4}$} & \multicolumn{4}{|c|}{ Sub-sample (1997:Q2-2009:Q4) } & \multicolumn{4}{|c|}{ Full sample (1997:Q2-2015:Q1) } \\
\hline & \multicolumn{8}{|c|}{ Panel (A.1) } \\
\hline & $\begin{array}{c}\text { Core } \\
\text { (UGDP) }\end{array}$ & $\begin{array}{l}\text { Core } \\
\text { (FS) }\end{array}$ & $\begin{array}{c}\text { PIIGS } \\
\text { (UGDP) }\end{array}$ & $\begin{array}{c}\text { PIIGS } \\
\text { (FS) }\end{array}$ & $\begin{array}{c}\text { Core } \\
\text { (UGDP) }\end{array}$ & $\begin{array}{c}\text { Core } \\
\text { (FS) }\end{array}$ & $\begin{array}{c}\text { PIIGS } \\
\text { (UGDP) }\end{array}$ & $\begin{array}{c}\text { PIIGS } \\
(\mathrm{FS})\end{array}$ \\
\hline Core (UGDP) & 14.9 & 4.8 & 2.3 & 3 & 16.9 & 2.4 & 2.8 & 3 \\
\hline Core (FS) & 3.1 & 15.6 & 1.7 & 4.6 & 5.9 & 11 & 2.8 & 5.3 \\
\hline PIIGS (UGDP) & 1.7 & 3.5 & 15.1 & 4.7 & 1.8 & 2.5 & 17.8 & 2.8 \\
\hline \multirow[t]{3}{*}{ PIIGS (FS) } & 3.2 & 11.5 & 2 & 8.3 & 3.2 & 4 & 2.6 & 15.2 \\
\hline & \multicolumn{8}{|c|}{$\underline{\text { Panel (A.2) }}$} \\
\hline & Within & $\begin{array}{l}\text { From } \\
\text { others }\end{array}$ & $\begin{array}{c}\text { To } \\
\text { others }\end{array}$ & Net & Within & $\begin{array}{l}\text { From } \\
\text { others }\end{array}$ & $\begin{array}{l}\text { To } \\
\text { others }\end{array}$ & Net \\
\hline Core (UGDP) & 14.9 & 10.1 & 8 & -2.1 & 16.9 & 8.1 & 10.9 & 2.7 \\
\hline Core (FS) & 15.6 & 9.4 & 19.8 & 10.5 & 11 & 14 & 8.9 & -5.1 \\
\hline PIIGS (UGDP) & 15.1 & 9.9 & 5.9 & -3.9 & 17.8 & 7.2 & 8.2 & 1 \\
\hline PIIGS (FS) & 8.3 & 16.7 & 12.2 & -4.5 & 15.2 & 9.8 & 11.2 & 1.3 \\
\hline Total & 54 & 46 & 46 & 0.0 & 60.8 & 39.2 & 39.2 & 0.0 \\
\hline
\end{tabular}

\begin{tabular}{|c|c|c|c|c|c|c|c|c|}
\hline \multirow[t]{3}{*}{$\mathbf{H}=\mathbf{8}$} & \multicolumn{4}{|c|}{ Sub-sample (1997:Q2-2009:Q4) } & \multicolumn{4}{|c|}{ Full sample (1997:Q2-2015:Q1) } \\
\hline & \multicolumn{8}{|c|}{ Panel (A.3) } \\
\hline & $\begin{array}{c}\text { Core } \\
\text { (UGDP) }\end{array}$ & $\begin{array}{l}\text { Core } \\
\text { (FS) }\end{array}$ & $\begin{array}{c}\text { PIIGS } \\
\text { (UGDP) }\end{array}$ & $\begin{array}{c}\text { PIIGS } \\
(\mathrm{FS})\end{array}$ & $\begin{array}{c}\text { Core } \\
\text { (UGDP) }\end{array}$ & $\begin{array}{c}\text { Core } \\
\text { (FS) }\end{array}$ & $\begin{array}{c}\text { PIIGS } \\
\text { (UGDP) }\end{array}$ & $\begin{array}{c}\text { PIIGS } \\
(\mathrm{FS})\end{array}$ \\
\hline Core (UGDP) & 12.53 & 6.38 & 2.69 & 3.39 & 14.94 & 2.90 & 3.42 & 3.74 \\
\hline Core (FS) & 2.60 & 15.61 & 2.02 & 4.77 & 5.07 & 9.76 & 3.76 & 6.41 \\
\hline PIIGS (UGDP) & 1.79 & 3.85 & 14.49 & 4.87 & 1.83 & 2.85 & 16.96 & 3.36 \\
\hline \multirow[t]{3}{*}{ PIIGS (FS) } & 2.55 & 12.24 & 2.51 & 7.70 & 2.60 & 4.12 & 3.50 & 14.78 \\
\hline & \multicolumn{8}{|c|}{ Panel (A.4): } \\
\hline & Within & $\begin{array}{l}\text { From } \\
\text { others }\end{array}$ & $\begin{array}{c}\text { To } \\
\text { others }\end{array}$ & Net & Within & $\begin{array}{l}\text { From } \\
\text { others }\end{array}$ & $\begin{array}{c}\text { To } \\
\text { others }\end{array}$ & Net \\
\hline Core (UGDP) & 12.5 & 12.5 & 6.9 & -5.5 & 14.9 & 10.1 & 9.5 & $\begin{array}{c}-0.6 \\
\end{array}$ \\
\hline Core (FS) & 15.6 & 9.4 & 22.5 & 13.1 & 9.8 & 15.2 & 9.9 & -5.4 \\
\hline PIIGS (UGDP) & 14.5 & 10.5 & 7.2 & -3.3 & 17 & 8 & 10.7 & 2.6 \\
\hline PIIGS (FS) & 7.7 & 17.3 & 13 & -4.3 & 14.8 & 10.2 & 13.5 & 3.3 \\
\hline Total & 50.3 & 49.7 & 49.7 & 0.0 & 56.4 & 43.6 & 43.6 & 0.0 \\
\hline
\end{tabular}


Table 5: (Continued)

Panel B: Common-Frequency Approach

\begin{tabular}{|c|c|c|c|c|c|c|c|c|}
\hline $\mathbf{H}=\mathbf{4}$ & \multicolumn{4}{|c|}{ Sub-sample (1997:Q2-2009:Q4) } & \multicolumn{4}{|c|}{ Full sample (1997:Q2-2015:Q1) } \\
\hline & \multicolumn{8}{|c|}{ Panel (B.1) } \\
\hline & $\begin{array}{c}\text { Core } \\
\text { (UGDP) }\end{array}$ & $\begin{array}{l}\text { Core } \\
\text { (FS) }\end{array}$ & $\begin{array}{c}\text { PIIGS } \\
\text { (UGDP) }\end{array}$ & $\begin{array}{c}\text { PIIGS } \\
\text { (FS) }\end{array}$ & $\begin{array}{c}\text { Core } \\
\text { (UGDP) }\end{array}$ & $\begin{array}{l}\text { Core } \\
\text { (FS) }\end{array}$ & $\begin{array}{c}\text { PIIGS } \\
\text { (UGDP) }\end{array}$ & $\begin{array}{r}\text { PIIGS } \\
(\mathrm{FS})\end{array}$ \\
\hline Core (UGDP) & 12.87 & 5.32 & 3.89 & 2.93 & 21.7 & 0.5 & 2.2 & 0.7 \\
\hline Core (FS) & 1.11 & 20.11 & 0.95 & 2.82 & 7 & 11.8 & 4 & 2.2 \\
\hline PIIGS (UGDP) & 4.92 & 4.82 & 9.78 & 5.48 & 1.9 & 0.7 & 21.7 & 0.7 \\
\hline \multirow[t]{3}{*}{ PIIGS (FS) } & 0.95 & 2.28 & 1.38 & 20.39 & 5 & 2 & 4.5 & 13.6 \\
\hline & \multicolumn{8}{|c|}{ Panel (B2) } \\
\hline & Within & $\begin{array}{l}\text { From } \\
\text { others }\end{array}$ & $\begin{array}{c}\text { To } \\
\text { others }\end{array}$ & Net & $\overline{\text { Within }}$ & $\begin{array}{l}\text { From } \\
\text { others }\end{array}$ & $\begin{array}{c}\text { To } \\
\text { others }\end{array}$ & Net \\
\hline Core (UGDP) & 12.9 & 12.1 & 7.0 & -5.2 & 21.7 & 3.3 & 13.9 & 10.5 \\
\hline Core (FS) & 20.1 & 4.9 & 12.4 & 7.5 & 11.8 & 13.2 & 3.2 & -10.0 \\
\hline PIIGS (UGDP) & 9.8 & 15.2 & 6.2 & -9.0 & 21.7 & 3.3 & 10.6 & 7.3 \\
\hline PIIGS (FS) & 20.4 & 4.6 & 11.2 & 6.6 & 13.6 & 11.4 & 3.6 & -7.8 \\
\hline Total & 63.2 & 36.8 & 36.8 & 0.0 & 68.7 & 31.3 & 31.3 & 0.0 \\
\hline
\end{tabular}

$\mathbf{H}=\mathbf{8} \quad$ Sub-sample (1997:Q2-2009:Q4)

Full sample (1997:Q2-2015:Q1)

\begin{tabular}{|c|c|c|c|c|c|c|c|c|}
\hline & \multicolumn{8}{|c|}{ Panel (B.3) } \\
\hline & $\begin{array}{c}\text { Core } \\
\text { (UGDP) }\end{array}$ & $\begin{array}{l}\text { Core } \\
\text { (FS) }\end{array}$ & $\begin{array}{c}\text { PIIGS } \\
\text { (UGDP) }\end{array}$ & $\begin{array}{c}\text { PIIGS } \\
(\mathrm{FS})\end{array}$ & $\begin{array}{c}\text { Core } \\
\text { (UGDP) }\end{array}$ & $\begin{array}{l}\text { Core } \\
\text { (FS) }\end{array}$ & $\begin{array}{c}\text { PIIGS } \\
\text { (UGDP) }\end{array}$ & $\begin{array}{c}\text { PIIGS } \\
(\mathrm{FS})\end{array}$ \\
\hline Core (UGDP) & 12.14 & 5.07 & 4.22 & 3.57 & 20.83 & 0.64 & 2.74 & 0.79 \\
\hline Core (FS) & 1.52 & 18.88 & 1.28 & 3.32 & 6.77 & 9.85 & 5.80 & 2.58 \\
\hline PIIGS (UGDP) & 5.81 & 4.69 & 8.46 & 6.05 & 2.00 & 0.85 & 21.28 & 0.88 \\
\hline PIIGS (FS) & 1.03 & 2.50 & 1.82 & 19.66 & 4.48 & 2.13 & 6.17 & 12.21 \\
\hline
\end{tabular}

\begin{tabular}{|c|c|c|c|c|c|c|c|c|}
\hline & \multicolumn{8}{|c|}{ Panel (B.4) } \\
\hline & Within & $\begin{array}{l}\text { From } \\
\text { others }\end{array}$ & $\begin{array}{c}\text { To } \\
\text { others }\end{array}$ & Net & Within & $\begin{array}{l}\text { From } \\
\text { others }\end{array}$ & $\begin{array}{c}\text { To } \\
\text { others }\end{array}$ & Net \\
\hline Core (UGDP) & 12.1 & 12.9 & 8.4 & -4.5 & 20.8 & 4.2 & 13.2 & 9.1 \\
\hline Core (FS) & 18.9 & 6.1 & 12.3 & 6.1 & 9.9 & 15.1 & 3.6 & -11.5 \\
\hline PIIGS (UGDP) & 8.5 & 16.5 & 7.3 & -9.2 & 21.3 & 3.7 & 14.7 & 11.0 \\
\hline PIIGS (FS) & 19.7 & 5.3 & 12.9 & 7.6 & 12.2 & 12.8 & 4.2 & -8.5 \\
\hline Total & 59.1 & 40.9 & 40.9 & 0.0 & 64.2 & 35.8 & 35.8 & 0.0 \\
\hline
\end{tabular}


Table 6: Macro-financial spillovers among EZ countries

\begin{tabular}{|c|c|c|c|c|c|c|c|c|}
\hline & \multicolumn{8}{|c|}{ Panel A.1: Mixed Frequency Approach $(\mathrm{H}=4)$} \\
\hline & \multicolumn{4}{|c|}{ Sub-sample 1997:Q2-2009:Q4 } & \multicolumn{4}{|c|}{ Full sample 1997:Q2-2015:Q1 } \\
\hline & Within & $\begin{array}{l}\text { From } \\
\text { others }\end{array}$ & $\begin{array}{c}\text { To } \\
\text { others }\end{array}$ & Net & Within & $\begin{array}{l}\text { From } \\
\text { others }\end{array}$ & $\begin{array}{c}\text { To } \\
\text { others }\end{array}$ & Net \\
\hline "AT" & 4.39 & 5.61 & 4.69 & -0.92 & 5.28 & 4.72 & 4.78 & 0.06 \\
\hline "BE" & 4.12 & 5.88 & 9.76 & 3.88 & 3.9 & 6.1 & 4.57 & -1.53 \\
\hline "FR" & 3.7 & 6.3 & 5.19 & -1.11 & 3.86 & 6.14 & 2.78 & -3.36 \\
\hline "DE" & 3.87 & 6.13 & 9.44 & 3.3 & 5.81 & 4.19 & 8.2 & 4.02 \\
\hline "NL" & 4.9 & 5.1 & 8.37 & 3.26 & 5.33 & 4.67 & 3.13 & -1.54 \\
\hline "GR" & 6.4 & 3.6 & 3.43 & -0.17 & 7.5 & 2.5 & 5.99 & 3.49 \\
\hline "IE" & 4.1 & 5.9 & 5.72 & -0.17 & 6.49 & 3.51 & 5.8 & 2.29 \\
\hline "IT" & 2.7 & 7.3 & 2.7 & -4.6 & 3.76 & 6.24 & 4.03 & -2.21 \\
\hline "PT" & 4.77 & 5.23 & 2.96 & -2.27 & 5.13 & 4.87 & 1.73 & -3.14 \\
\hline "ES" & 3.43 & 6.57 & 5.36 & -1.21 & 4.86 & 5.14 & 7.06 & 1.92 \\
\hline Total: & 42.4 & 57.6 & 57.6 & $\mathbf{0}$ & 51.9 & 48.1 & 48.1 & $\mathbf{0}$ \\
\hline Total core: & 21 & 29 & 37.4 & 8.4 & 24.2 & 25.8 & 23.5 & -2.3 \\
\hline Total PIIGS: & 21.4 & 28.6 & 20.2 & -8.4 & 27.7 & 22.3 & 24.6 & 2.3 \\
\hline
\end{tabular}

Panel A.2: Mixed Frequency Approach $(\mathbf{H}=\mathbf{8})$

\begin{tabular}{|c|c|c|c|c|c|c|c|c|}
\hline & \multicolumn{4}{|c|}{ Sub-sample 1997:Q2-2009:Q4 } & \multicolumn{4}{|c|}{ Full sample 1997:Q2-2015:Q1 } \\
\hline & Within & $\begin{array}{l}\text { From } \\
\text { others }\end{array}$ & $\begin{array}{c}\text { To } \\
\text { others }\end{array}$ & Net & Within & $\begin{array}{c}\text { From } \\
\text { others }\end{array}$ & $\begin{array}{c}\text { To } \\
\text { others }\end{array}$ & Net \\
\hline "AT" & 3.77 & 6.23 & 4.07 & -2.16 & 4.79 & 5.21 & 5.19 & -0.02 \\
\hline "BE" & 3.13 & 6.87 & 8.71 & 1.84 & 3.23 & 6.77 & 4.55 & -2.22 \\
\hline "FR" & 3.04 & 6.96 & 5.22 & -1.74 & 3.15 & 6.85 & 2.40 & -4.45 \\
\hline "DE" & 3.87 & 6.13 & 13.46 & 7.33 & 5.09 & 4.906 & 8.16 & 3.25 \\
\hline "NL" & 4.22 & 5.78 & 8.06 & 2.29 & 4.58 & 5.42 & 2.92 & -2.50 \\
\hline "GR" & 5.49 & 4.51 & 3.31 & -1.20 & 7.30 & 2.70 & 5.65 & 2.94 \\
\hline "IE" & 4.05 & 5.95 & 6.89 & 0.94 & 6.38 & 3.62 & 6.65 & 3.02 \\
\hline "IT" & 2.36 & 7.64 & 2.89 & -4.75 & 3.26 & 6.74 & 4.71 & -2.03 \\
\hline "PT" & 4.34 & 5.66 & 2.69 & -2.97 & 4.57 & 5.43 & 1.65 & -3.78 \\
\hline "ES" & 3.40 & 6.60 & 7.02 & 0.42 & 4.81 & 5.19 & 10.97 & 5.78 \\
\hline Total: & 37.67 & 62.33 & 62.33 & 0.00 & 47.14 & 52.86 & 52.86 & 0.00 \\
\hline Total core: & 18.03 & 31.97 & 39.53 & 7.56 & 20.84 & 29.16 & 23.23 & -5.93 \\
\hline Total PIIGS: & 19.64 & 30.36 & 22.80 & -7.56 & 26.31 & 23.69 & 29.62 & 5.93 \\
\hline
\end{tabular}


Table 6: (Continued)

\begin{tabular}{|c|c|c|c|c|c|c|c|c|}
\hline & \multicolumn{8}{|c|}{ Panel B.1: Common-Frequency Approach $(\mathrm{H}=4)$} \\
\hline & \multicolumn{4}{|c|}{ Sub-sample 1997:Q2-2009:Q4 } & \multicolumn{4}{|c|}{ Full sample 1997:Q2-2015:Q1 } \\
\hline & Within & $\begin{array}{c}\text { From } \\
\text { others }\end{array}$ & $\begin{array}{c}\text { To } \\
\text { others }\end{array}$ & Net & Within & $\begin{array}{l}\text { From } \\
\text { others }\end{array}$ & $\begin{array}{c}\text { To } \\
\text { others }\end{array}$ & Net \\
\hline "AT" & 6.16 & 3.84 & 4.89 & 1.05 & 6.44 & 3.56 & 4.32 & 0.76 \\
\hline "BE" & 4.53 & 5.47 & 4.62 & -0.86 & 4.73 & 5.27 & 2.18 & -3.09 \\
\hline "FR" & 5.14 & 4.86 & 5.23 & 0.37 & 5.34 & 4.66 & 1.96 & -2.70 \\
\hline "DE" & 5.41 & 4.59 & 5.87 & 1.28 & 7.28 & 2.72 & 8.04 & 5.33 \\
\hline "NL" & 7.19 & 2.81 & 3.33 & 0.52 & 7.07 & 2.93 & 3.15 & 0.22 \\
\hline "GR" & 6.01 & 3.99 & 3.78 & -0.21 & 8.16 & 1.84 & 3.01 & 1.16 \\
\hline "IE" & 4.58 & 5.42 & 2.77 & -2.65 & 7.22 & 2.78 & 3.41 & 0.64 \\
\hline "IT" & 6.35 & 3.65 & 7.20 & 3.55 & 5.24 & 4.76 & 3.39 & -1.37 \\
\hline "PT" & 6.46 & 3.54 & 1.93 & -1.61 & 6.05 & 3.95 & 1.70 & -2.24 \\
\hline "ES" & 4.47 & 5.53 & 4.09 & -1.45 & 5.96 & 4.04 & 5.34 & 1.30 \\
\hline Total: & 56.29 & 43.71 & 43.71 & 0.00 & 63.48 & 36.52 & 36.52 & 0.00 \\
\hline Total core: & 28.42 & 21.58 & 23.95 & 2.37 & 30.85 & 19.15 & 19.66 & 0.51 \\
\hline Total PIIGS: & 27.87 & 22.13 & 19.76 & -2.37 & 32.63 & 17.37 & 16.86 & -0.51 \\
\hline
\end{tabular}

Panel B.2: Common-Frequency Approach $\mathbf{( H = 8 )}$

\begin{tabular}{|c|c|c|c|c|c|c|c|c|}
\hline & \multicolumn{4}{|c|}{ Sub-sample 1997:Q2-2009:Q4 } & \multicolumn{4}{|c|}{ Full sample 1997:Q2-2015:Q1 } \\
\hline & Within & $\begin{array}{l}\text { From } \\
\text { others }\end{array}$ & $\begin{array}{c}\text { To } \\
\text { others }\end{array}$ & Net & Within & $\begin{array}{l}\text { From } \\
\text { others }\end{array}$ & $\begin{array}{c}\text { To } \\
\text { others }\end{array}$ & Net \\
\hline "AT" & 5.64 & 4.36 & 5.27 & 0.91 & 5.97 & 4.03 & 4.11 & 0.08 \\
\hline "BE" & 3.77 & 6.23 & 4.22 & -2.01 & 4.07 & 5.93 & 2.22 & -3.71 \\
\hline "FR" & 4.76 & 5.24 & 6.11 & 0.87 & 4.65 & 5.35 & 1.71 & -3.64 \\
\hline "DE" & 4.71 & 5.29 & 7.14 & 1.85 & 6.77 & 3.23 & 7.76 & 4.53 \\
\hline "NL" & 6.65 & 3.35 & 3.36 & 0.01 & 6.60 & 3.40 & 3.69 & 0.30 \\
\hline "GR" & 5.67 & 4.33 & 4.12 & -0.20 & 8.05 & 1.95 & 2.98 & 1.04 \\
\hline "IE" & 3.95 & 6.05 & 3.29 & -2.77 & 6.96 & 3.04 & 3.82 & 0.77 \\
\hline "IT" & 6.02 & 3.98 & 8.46 & 4.48 & 4.58 & 5.42 & 3.61 & -1.81 \\
\hline "PT" & 5.72 & 4.28 & 1.76 & -2.52 & 5.26 & 4.74 & 1.67 & -3.07 \\
\hline "ES" & 4.12 & 5.88 & 5.27 & -0.62 & 5.96 & 4.04 & 9.56 & 5.52 \\
\hline Total: & 50.99 & 49.01 & 49.01 & 0.00 & 58.87 & 41.13 & 41.13 & 0.00 \\
\hline Total core: & 25.52 & 24.48 & 26.11 & 1.63 & 28.05 & 21.95 & 19.49 & -2.45 \\
\hline Total PIIGS: & 25.47 & 24.53 & 22.90 & -1.63 & 30.81 & 19.19 & 21.64 & 2.45 \\
\hline
\end{tabular}

